\title{
EFFECT OF SODIUM VALPROATE ON THE STRUCTURE OF THE RENAL CORTEX OF ADULT MALE ALBINO RAT AND THE ROLE OF CINNAMON
}

\author{
By
Mona H. M. A. Hamouda, Fatma S. Abdel Aal and Fattoma H. Y.El- Mashad \\ Histology Department, Faculty of Medicine (Girls), Al-Azhar University, Cairo, Egypt
}

\begin{abstract}
Background: Valproic Acid (VPA) is one of the most widely prescribed antiepileptic drugs and is regarded as a first choice for most forms of seizures. Although valproic acid has a wide therapeutic window, yet it is associated with many adverse effects.

Objectives: Evaluation of the effect of sodium valproate on renal cortex structure of adult male albino rats, and the role of cinnamon.

Materials and Methods: Twenty four adult male albino rats weighing 160-180 grams were divided into four equal groups: Group I: control group, group II: sodium valproate group $(500 \mathrm{ml} / \mathrm{kg} / \mathrm{day}$ orally), group III: Cinnamon extract group ( $4 \mathrm{ml} /$ rat/day orally) and group IV: sodium valproate and cinnamon extract group. Drugs were given orally once daily for four weeks.

Kidney samples were collected for histological, imunohistochmical and ultrastructural studies. Blood urea nitrogen (BUN) and serum creatinine ( $\mathrm{sCr}$ ) concentration were measured. Morphometric quantitative study for area percentage of collagen fibers and Caspase- $3+v e$ cells were done.

Results: Examination of the renal cortex of sodium valproate ingested group demonstrated atrophied glomerulus with collapsed tuft, widening of bowman's space, degenerated tubule, hemorrhage and cellular infiltration. Moreover, the collagen fibers increased as well as focal loss of the basement membrane and brush border of the tubules. Caspase- 3 +ve cells significantly increased after sodium valproate administration. Rarefaction of the cytoplasm, degeneration of mitochondria, loss of apical microvilli and pyknotic nucleus were observed in the electron microscopically study.

The kidney functions demonstrated significant increase in concentration of blood urea nitrogen (BUN) and serum creatinine $(\mathrm{sCr})$. In contrast, cinnamon extract administration with sodium valproate ingested group showed some amelioration in the renal cortex structure and function.
\end{abstract}

Conclusion: Sodium valproate aggravated the histological structure of the renal cortex. However, cinnamon extract could ameliorate the changes due to its antioxidants effect.

Key words: Sodium valproate, Cinnamon extract, renal cortex.

\section{INTRODUCTION}

Valproic acid is an antiepileptic drug composed of eight carbon branched chain fatty acid with a broad spectrum anticonvulsant activity, commonly used for over 30 years (Pourahmad et al., 2012). It was approved by Food and Drug 
MONA H. M. A. HAMOUDA et al.,

Administration (FDA) for treatment of epilepsy either as mono therapy or in combination with other antiepileptic drugs (Loscher, 2002). It was added as one of the mood stabilizing agents in patients with affective and anxiety disorder and as a prophylactic treatment of migraine (Maneenin et al., 2018).

The increased clinical use of valproic acid has been accompanied by reports of hepatic dysfunction and renal tubular defects (Toktam et al., 2012). It has been reported in several articles that Fanconi syndrome was associated with valproic acid therapy (Dhillon \& H?gler, 2011 and Heidari et al., 2018). Although the exact biochemical mechanisms of valproic acid toxicity to kidney have not been well defined, several hypothesis have been proposed. The recent hypothesis suggests an involvement of peroxidative injury in valproic acid induced renal tubular disorder (Amrani et al., 2016).

Herbal medicine is the commonest member of complementary and alternative medicine and it has been used in the treatment of many diseases (Jaya et al., 2014).

Cinnamon is one of the most widely used plants in herbal medicines with diverse bioactive effects. It is obtained from the inner bark of several trees from the genus Cinnamomum (Abdelwahab et al., 2014). Cinnamon may serve as potential dietary source of natural antioxidants for improving human nutrition and health (Su et al., 2007 and AL-Khamas, 2018). It is rich in natural polyphenolic compound. Polyphenols act as reactive oxygen and nitrogen species scavengers, redox active transition metal chelators and enzyme modulators
(Morgan et al., 2014 and Beji et al., 2018).

It is a traditional remedy for dyspeptic conditions like ?atulence, gastrointestinal spasms, loss of appetite, and diarrhea. It is also used to improve the ?avor of other non-medicinal products. In folk medicine it is used to treat colds, nausea, in? ammation, rheumatism, vomiting, and menstrual disorders. It has carminative and astringent properties. The available in vitro and animal in vivo evidence suggests that cinnamon has antiin? ammatory, antimicrobial, antibacterial, antioxidant, antitumor, cardiovascular, cholesterollowering, and immunomodulatory effects ( Du et al., 2009; Lee et al., 2011 ; Mandal et al., 2011 ; Wang et al., 2011 and Charles, 2013).

This work aimed to investigate the changes of sodium valproate on renal cortex structure; imunohistochmical expression and kidney function of adult male albino rats and evaluate the possible protective role of cinnamon extract.

\section{MATERIALS AND METHODS}

Twenty four adult male Wister strain albino rats (160-180 g) were used in the present experiment. They were obtained from the Nile Company for Pharmaceutical and Chemical Industries, Cairo, Egypt. The animals were housed in plastic cages $(35 \times 30 \times 35) 6$ rats per cage in the animal house in the Faculty of Medicine for Girls, Al-Azhar University. They were equally divided into four groups:

GI: Control group, GII: Sodium valproate group $(500 \mathrm{ml} / \mathrm{kg} /$ day - Jassim, 2013) for four weeks. Sodium valproate was purchased from pharmacy in the form 
of syrup with a trade name (Depakine) containing $5.764 \mathrm{~g}$ sodium valproate $1100 \mathrm{ml}$. It was produced by Global Napi Pharmaceuticals for Sanaofi, Egypt, G III: Cinnamon extract group (4ml/rat/day -Hasanein et al., 2012) for four weeks. The cinnamon bark was purchased from the local market, Cairo, Egypt. The bark was finally powdered in a mechanical mixer $(5 \mathrm{~g}$ powder was dissolved in $100 \mathrm{ml}$ water and boiled together for $2 \mathrm{~min}$, then solution was cooled to room temperature and then filtered - Hasanein et al., 2012). G IV: Sodium valproate/ Cinnamon extract group as previously mentioned regimen.

Light microscopic examination: Kidney samples were collected, fixed in $10 \%$ formalin solution for 3 days, dehydrated in graded alcohol series, embedded in paraffin wax then thin sections of 5 ? $\mathrm{m}$ thickness were obtained. Sections were stained with H\&E for routine histological examination, Sirius red stain for staining collagen fibers, PAS stain for basement membrane and brush border, morphometric analysis (Bancroft and Gamble, 2015).

Electron microscopic study: The specimens were immediately fixed in $5 \%$ glutaraldehyde in $0.1 \mathrm{M}$ sodium cacodylate buffer, at $0-4^{\circ} \mathrm{C}$ and $\mathrm{pH} 7.3$ for 8 hours (Robinson et al., 1987). The specimens were washed for 1.5 hour with 3 changes of the same buffer. Then fixed in $1 \%$ Osmium tetraoxide in the same cacodylate buffer for 2 hours. At first, $0.5 \mu \mathrm{m}$ semithin sections were cut, picked up on a glass slides and stained with toluidine blue for light microscopic examination to locate the desired area. Ultra-thin sections were then cut and examined under a JEOL 100s transmission electron microscope at $60 \mathrm{kV}$ accelerating voltage, at Histology Department, Faculty of Medicine for Girls, Al-Azhar University. a Jeol 100s (Japan) (William and Carter, 1996).

Imunohistochmical study: Caspase-3 (diluted 1:50) was used for detection of apoptosis in the tubular cells. Paraffin sections of the kidney were cut at $5 ? \mathrm{~m}$ thickness on positively charged slides and incubated at $42^{\circ} \mathrm{C}$ in an oven for $24 \mathrm{~h}$. Sections were deparaffinized in xylene (1 PAS), hydrated in descending grade of alcohol, and incubated in hydrogen peroxide $(5 \mathrm{~min})$. They were thin washed twice in phosphate buffered saline (PBS) (5 min each). Primary antibody was applied to the sections, which were incubated for $(1.5 \mathrm{~h})$. Then the specimens were washed in PBS for 5 minute each. Secondary antibody was applied and the sections were again incubated for $20 \mathrm{~min}$, followed by washing 3 times in PBS for 5 min each. Diaminobenzidine tetrahydrocholride solution was applied to the sections and they were further incubated for $10 \mathrm{~min}$ (Bancroft and Gamble, 2015). The sections were washed in distilled water and countered stained with Mayer's hematoxylin (2 min). There after washed in tap water, cleared, and mounted by DPX.

Serological study: At the end of the experiment the animals were anesthetized by ether inhalation and blood samples were collected from the orbital sinuses of each rat to estimate the concentration of serum creatinine $(\mathrm{sCr})$ and blood urea nitrogen (BUN). 
MONA H. M. A. HAMOUDA et al.,

Quantitative morphometric study: The area percentage of collagen fibers was measured in sirus red stained sections.

Caspase-3 stained sections were examined for area percent of Caspase-3 +ve cells.

The measurements were obtained using computer-based image analysis soft-ware (Leica Qwin 500; Imaging Systems, Cambridge, UK) at the image analyzing unit of the pathology department, faculty of dentistry, Cairo University - Egypt. Measurements were performed in 10 nonoverlapping fields for each group $\times 400$ magnification. Mean value and standard deviation were obtained from each specimen for statistical analysis.

Statistical Analysis: All statistical analysis were performed using the statistical software package SPSS. The obtained data were expressed as mean \pm standard deviation and analyzed using analysis of variance (ANOVA) followed by Post hoc test (Tukey) to judge the difference between various groups. The statistical significance level was defined as $\mathrm{p} \leq 0.05$.

\section{RESULTS}

H\&E: Light microscopic examination of the renal cortex sections control group (GI) showed renal corpuscles, proximal and distal convoluted tubules. Renal corpuscle formed of a glomerulus surrounded by visceral and partial layers of Bowman's capsules which were separated by Bowman's spaces. The proximal convoluted tubules (PCTs) were lined with high cuboidal cells, they had ill-defined cell boundaries and apical brush borders. The distal convoluted tubules (DCTs) were lined with low cubical cells (Figs 1, 2\&3). Sodium valproate group (GII): Examination of the renal cortex sections, showed marked alteration of the renal cortex when compared to the control group. Many renal corpuscles showed shrinkage of their glomerular tuft of capillaries with widening of their capsular space. Few corpuscles revealed distortion of their normal appearance. Many tubular cells showed extensive vacuolation of the cytoplasm. Some nuclei of these cells were deeply stained, displaced towards the lumen or even lost (Figs 4 A \& B.). In addition to the above changes, many section of this group revealed interstitial mononuclear cellular infiltrations around renal corpuscles and tubules. Increased deposition of connective tissue elements around renal corpuscles and tubules noticed in some sections (Figs. 5\&6). Other sections revealed interstitial hemorrhage (Fig. 6). Cinnamon extract group (GIII) showed normal histological appearance of the renal cortex comparing with control (Fig.7). Sodium valproate/ Cinnamon extract group (GIV) revealed prominent structure improvement when compared to Sodium valproate group (GII). The glomerular tufts appeared nearly similar to control (Fig. 8). However, some renal corpuscles had slightly wide Bowman's spaces. The tubular lining epithelial cells appeared continuous in many tubules with normal appearance. Other tubules showed cytoplasmic vaculation of their lining epithelium. Mild congestion of peritubular capillaries was also noticed (Fig. 8). 
Periodic acid Schiff (PAS): Stained sections (GI) revealed normal PAS positive $(+v e)$ reaction in the renal corpuscles and in the apical brush border of proximal convoluted tubule and the basement membrane surrounding the renal tubules (Fig.9). GII revealed mild to week positive PAS reaction in the basement membrane surrounding renal corpuscles and glomerular capillaries together with focal loss of basement membrane around most tubules. There was also loss of the brush border of the proximal convoluted tubules (Fig.10). GIII revealed normal PAS positive (+ve) reaction in the renal corpuscles and renal tubules. It mainly appeared in the apical brush border of proximal convoluted tubule and the basement membrane surrounding the renal tubules (Fig.11) GIV revealed PAS positive reaction as compared to the sodium valproate group. A positive PAS reaction was observed in the basement membrane surrounding renal corpuscles and glomerular capillaries. Some renal tubule had increase positive PAS reaction in the basement membrane however; others showed focal loss of their basement membrane. There was also focal loss of the brush border of the cells lining some proximal convoluted tubules (Fig.12).

Sirius red staining: GI revealed normal distribution of collagen fibers which appeared as fine collagen fibers "stained red" among the glomerular basement membranes and inbetween the renal tubules (Fig.13). GII showed marked deposition of collagen fibers "stained red" around the renal corpuscles and tubules (Fig.14) as compared to the control group as well as around blood vessels (Fig.15). GIII showed normal distribution of collagen fibers among the glomerular basement membranes and inbetween the renal tubules (Fig.16). GIV showed moderate decrease amount of collagen fibers around the renal corpuscles and tubules as compared to sodium valproate group (Fig.17).

Imunohistochmical study for Caspase-3: GI showed negative (-ve) immune reaction within the cytoplasm of the tubular cell. (Fig.18). GII showed strong positive (+ve) immunostaining reaction for Caspase- 3 in the form of dark brown granules within the cytoplasm (Fig.19). GIII showed negative (-ve) immune reaction within the cytoplasm of the tubular cell (Fig.20). GIV revealed tubular cells with moderate cytoplasmic immunoreaction in the form of dark brown granules (Fig. 21).

\section{Electron microscopic study :}

Control adult male albino rat (GI) revealed the normal ultrastructure features of the PCT. The cells had many apical closely packed microvilli and rested on a thin regular and well-defined basement membrane (Fig. 22). Multiple pinocytic vesicles, Golgi apparatus and lysosomes were also seen. There were also multivesicular bodies (secondary lysosomes) within the cytoplasm of cells of PCT (Fig. 23).

Sodium valproate ingested adult male albino rat (GII), revealed ultrastructual alteration as compared to that of the control group. The cells of the PCT showed extensive vacuolated coarse poorly defined cytoplasm and numerous swollen, sticky and degenerated mitochondria dissociated from the basal infolding. Nuclei with irregular nuclear envelop and partial loss of the apical microvilli were also seen (Fig. 24). Some of these tubules revealed small sized pyknotic nucleus with loss of their nuclear membrane and condensation of their chromatin and rarefied cytoplasm with focal thickening of basement membrane (Fig. 25). Other tubular cells showed disruption of apical cell membrane and loss of apical microvilli with extrusion of 
their content into the lumen (Fig.26). Cytoplasmic vacuolation were also seen (Fig. 27). Increase deposition of cross and longitudinal sections of collagen fibers and connective tissue cells around tubules were observed (Figs.27\&25). Interstitial hemorrhage in between the tubules was also seen (Fig.28).

Cinnamon extract ingested adult male albino rat (GIII) revealed the normal ultrastructure features of the PCT. The cells had many apical closely packed microvilli and rested on a thin regular and well-defined basement membrane. The basal part showed longitudinal deep basal infoldings extending almost entire height of the cell. They had rounded euchromatic nuclei. The nuclei were surrounded by nuclear envelope. The cytoplasm of cells revealed oval, rounded and elongated mitochondria which were arranged along deep basal infoldings parallel to the longitudinal axis of the cells. Multiple pinocytic vesicles beneath the microvilli and lysosomes were also seen (Fig.29).

Sodium valproate/ Cinnamon extract group (GIV) revealed prominent ultrastructure improvement when compared to Sodium valproate group (GII). The cells of the PCT appeared nearly similar to control except few mitochondria were degenerated and presence of vacuole at the basal part (Fig.30).

Blood urea nitrogen (BUN): The highest mean BUN was observed in GII
$(62.38 \pm 9.56)$, while the least mean was observed in GI and GIII $(29.1 \pm 5.7$ and $29.12 \pm 3.87)$ respectively. The mean BUN of the treated group GIV reduced $(46.1 \pm 4.39)$. All these values were of statistically significant differences (Table 1).

Serum creatinine level ( $\mathrm{sCr}$ ): The highest mean $\mathrm{sCr}$ was observed in GII (1.76 \pm 0.37$)$. However, the least mean was observed in GI $(0.42 \pm 0.07)$, followed by GIII $(0.48 \pm 0.18)$. The mean serum creatinine of the treated group GIV reduced $(1.38 \pm 0.20)$. These results were statistically significant (Table 1).

\section{Quantitative morphometric study:}

Statistical results of area percentage of collagen fibers in sirus red stained sections in all groups: The highest mean was observed in GII (42.39 \pm 28.75$)$, while the least mean was observed in GI and GIII (7.02 \pm 1.1 and $7.18 \pm 1.66)$. The mean area percentage of collagen fibers in treated group GIV reduced $(17.6 \pm 1.53)$. These results were statistically significant (Table 1).

Statistical results of Caspase-3 expression using area percent in all groups: The highest mean was observed in GII $(19.76 \pm 3.11)$, while the least mean was observed in GI and GIII (1.74 \pm 0.33 and $1.44 \pm 0.217)$. The mean area percentage of Caspase-3 expression in treated group GIV decreased (12.64 \pm 2.2 ). These results were statistically significant (Table 1). 


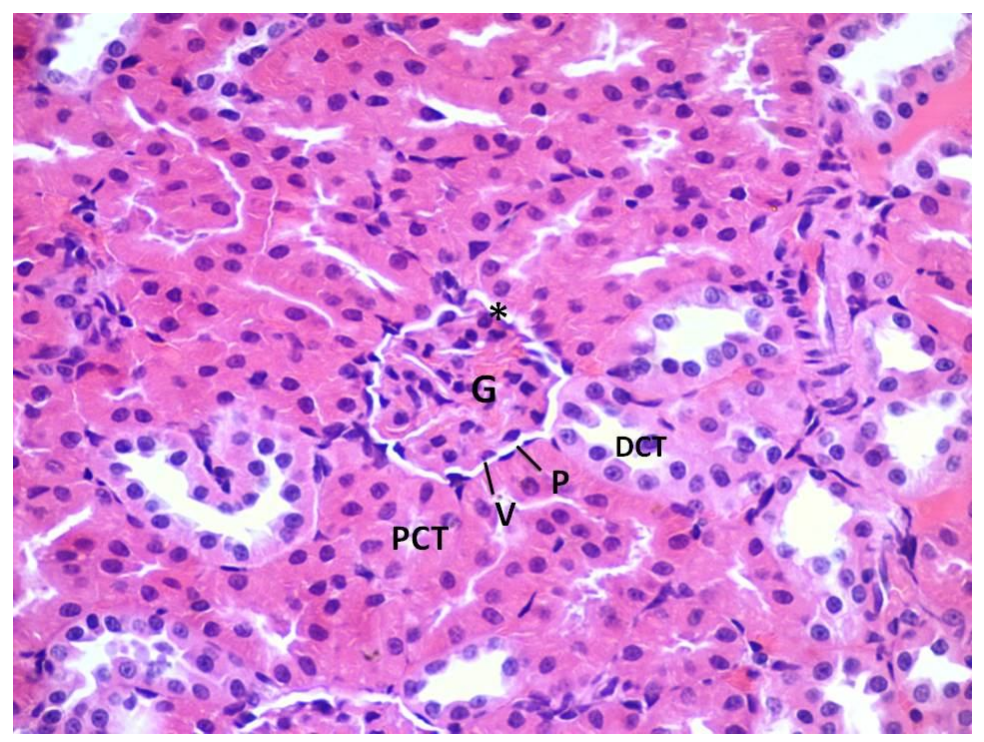

Fig (1): Showing renal corpuscles consisting of glomerulus $(\mathrm{G})$ surrounded by visceral (V) and parietal $(\mathrm{P})$ layers of Bowman's capsules which separated by Bowman's space (*). Notice, the proximal (PCT) and distal convoluted tubules (DCT)

(Control-H\&E x400)

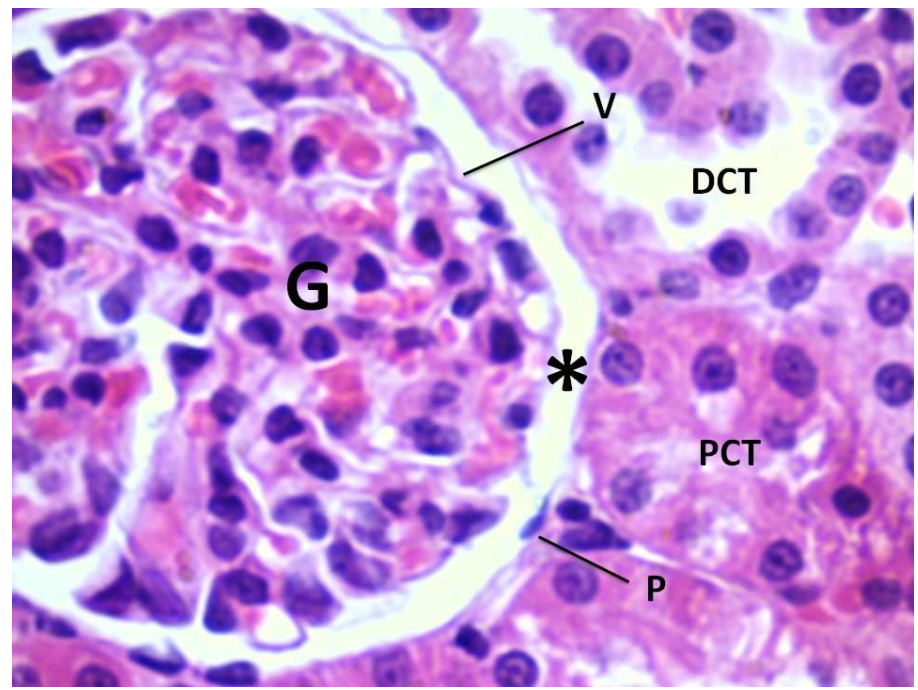

Fig (2): Showing a part of renal corpuscle consisting of glomerulus (G) surrounded by visceral (V) and parietal (P) layers of Bowman's capsule. The two layers are separated by Bowman's space (*). Notice, The proximal convoluted tubules (PCT) are lined with high cuboidal cells with ill-defined cell boundaries and apical brush borders. Distal convoluted tubules (DCT) showing wider lumina and are lined with cubical cells.

(Control- H\&E x1000) 


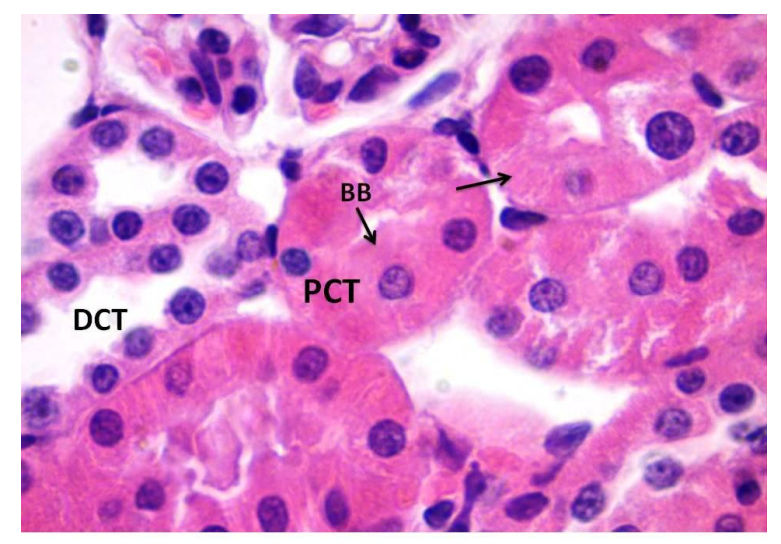

Fig (3): Showing proximal convoluted tubules (PCT) are lined with high cuboidal cells with basal rounded vesicular nuclei, and have ill-defined cell boundaries, apical brush borders $(\mathrm{BB})$ and basal striation $(\rightarrow)$. Distal convoluted tubules (DCT) showing wider lumina and are lined with cubical cells with rounded central nuclei.

\section{(Control -H\&E x1000)}

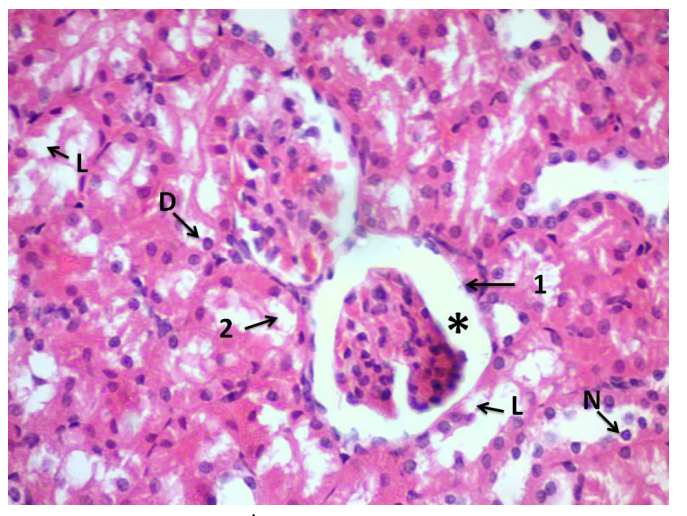

A

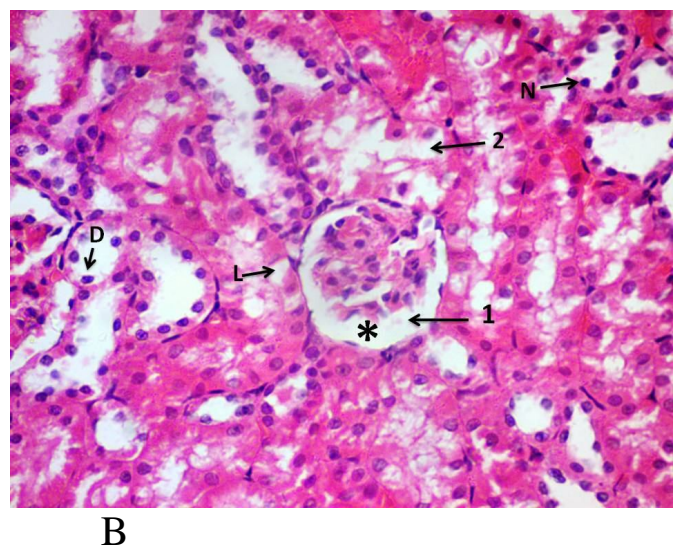

B

Fig (4 A\&B): Showing a renal corpuscle with shrinkage of its glomerular tuft of capillaries $(1 \rightarrow)$ and widening of its capsular space $\left(^{*}\right)$. Many tubular cells showing extensive vacuolation of the cytoplasm $(2 \rightarrow)$. Some nuclei of these cells are deeply stained $(\mathrm{N})$, displaced towards the lumen (D) or even lost (L)

(Sodium valproate ingested group $\mathrm{H} \& \mathrm{E}$ x400) 


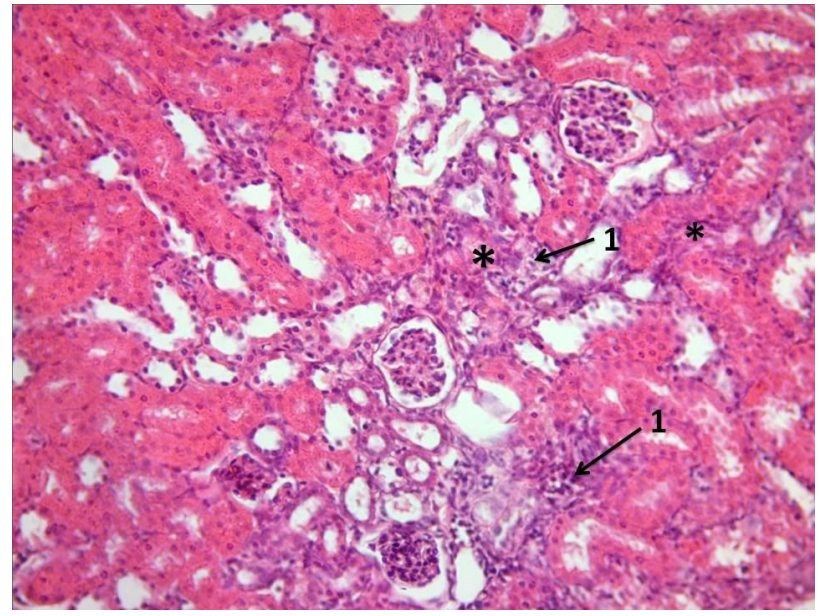

Fig (5): Showing interstitial mononuclear cellular infiltrations around renal corpuscles and tubules $(1 \rightarrow)$ and increase deposition of connective tissue elements around renal corpuscles and tubules also seen $(*)$.

(Sodium valproate ingested group H\&E x200)

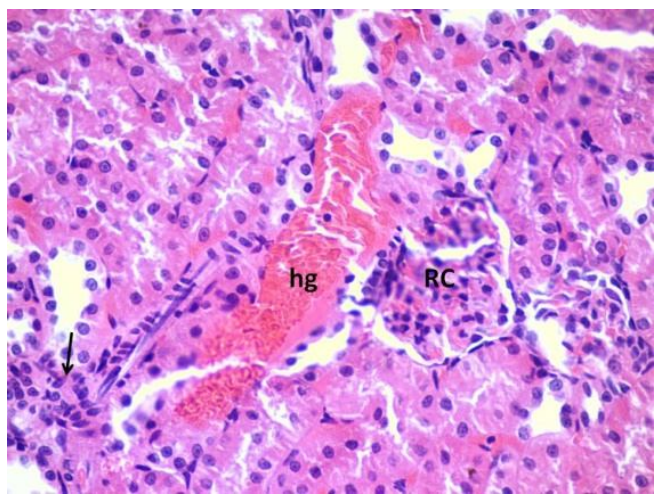

Fig (6): Showing interstitial hemorrhage in between the tubules (hg). Notice, the renal corpuscle of distorted shape (RC), and the interstitial mononuclear cellular infiltration around renal corpuscle and tubules $(\rightarrow)$.

(Sodium valproate ingested group H\&E x400) 


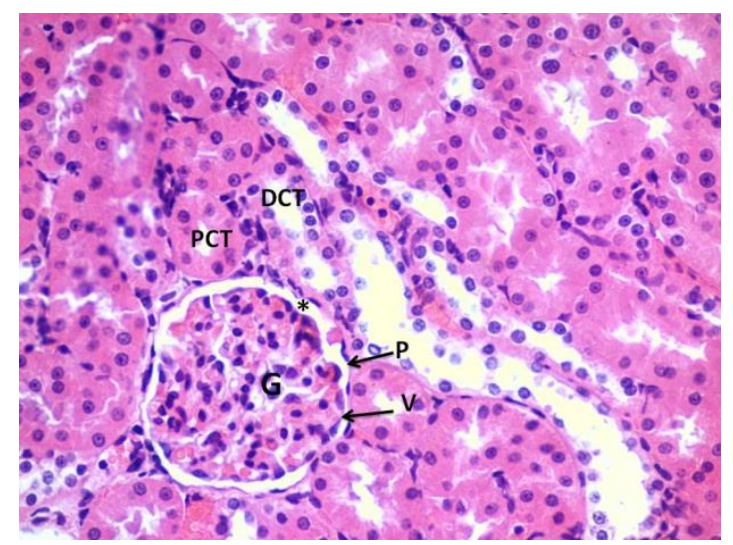

Fig (7): Showing a renal corpuscles consisting of glomerulus (G) surrounded by visceral (V) and parietal (P) layers of Bowman's capsules of Bowman's capsule which formed of simple squamous epithelium. The two layers are separated by Bowman's space (*). Notice, The proximal convoluted tubules (PCT) are lined with high cuboidal cells, with illdefined cell boundaries, and apical brush borders. Distal convoluted tubules (DCT) showing wider lumina and are lined with cubical cells with rounded central nuclei

(Cinnamon extract ingested group -H\&E x400)

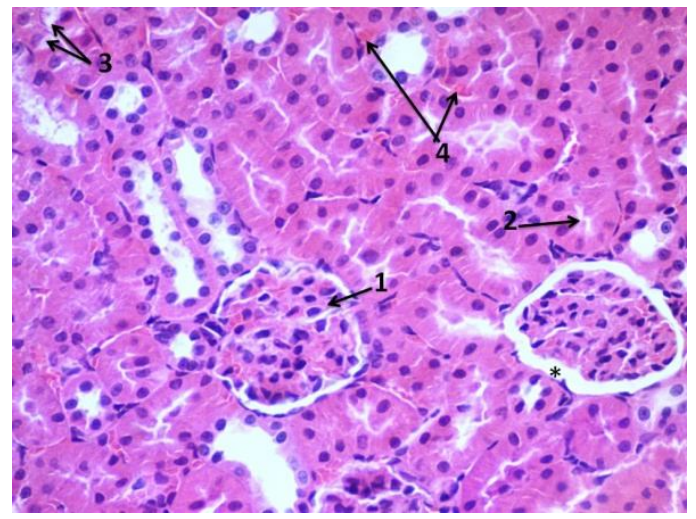

Fig (8): Showing a normal renal corpuscle $(1 \rightarrow)$ and another one with slightly wide Bowman's spaces (*). Some convoluted tubules show continuous lining epithelial cells with normal appearance $(2 \rightarrow)$. However, other tubules show cytoplasmic vacuolation of their lining epithelium $(3 \rightarrow)$. Mild congestion of peritubular capillaries is also noticed $(4 \rightarrow)$.

(Sodium valproate/ Cinnamon extract ingested group - H\&E x400) 


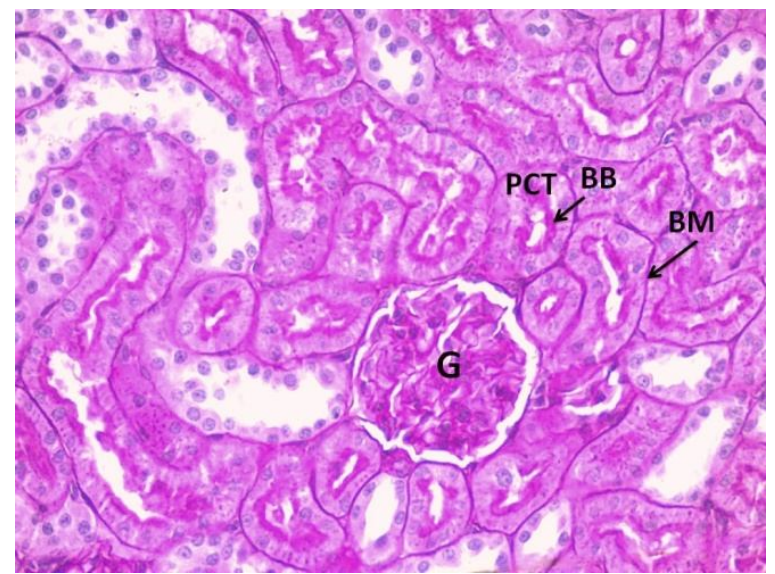

Fig (9): Showing normal PAS positive reaction in the glomerular capillaries $(G)$, in the basement membranes (BM) of tubules and in the apical brush borders (BB) of the proximal convoluted tubules (PCT).

(control -PAS x 400)

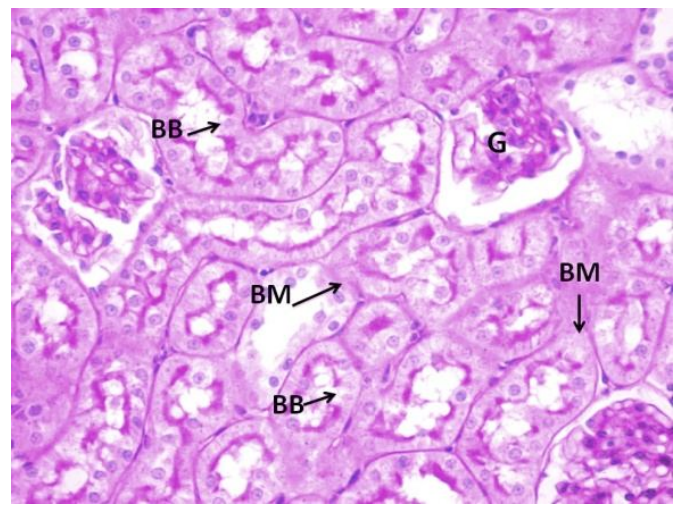

Fig (10): Showing decrease of the positive (PAS) reaction in the basement membrane surrounding glomerular capillaries $(\mathrm{G})$ with partial interruption of basement membrane around tubules (BM). Notice, loss of the apical brush border of almost cells lining the proximal convoluted tubules (BB).

(Sodium valproate ingested group PAS x400)

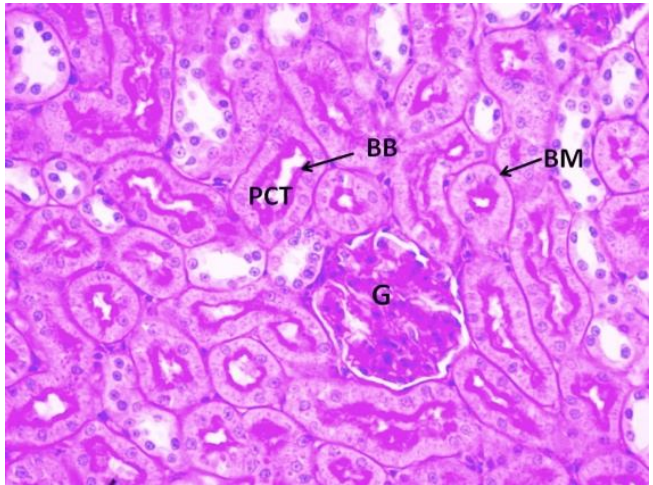

Fig (11): Showing normal PAS positive reaction in the glomerular capillaries (G), in the basement membranes (BM) of tubules and in the apical brush borders (BB) of the proximal convoluted tubules (PCT).

(Cinnamon extract ingested group PAS x 400) 


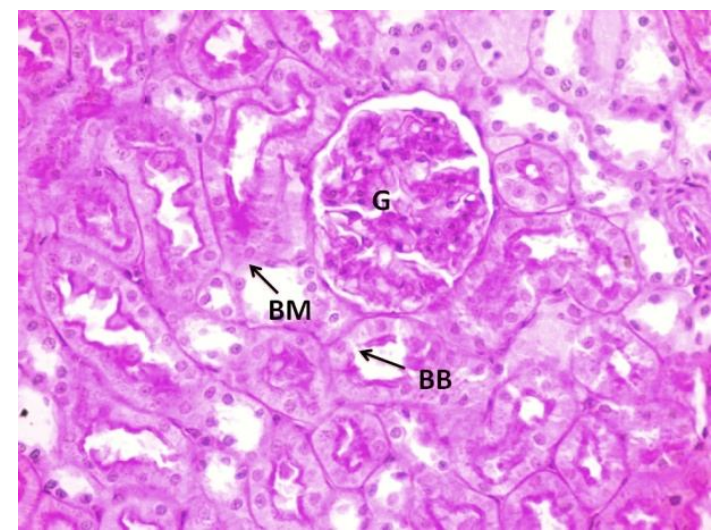

Fig (12): Showing increase (PAS) positive reaction in the basement membrane surrounding glomerular capillaries $(G)$ and tubules. Some renal tubule showing increase positive PAS reaction in the basement membrane however; others are showing focal loss of their basement membrane (BM). Notice, focal loss of the apical brush border of some cells lining the proximal convoluted tubules (BB).

(Sodium valproate/ Cinnamon extract ingested group - PAS x400)

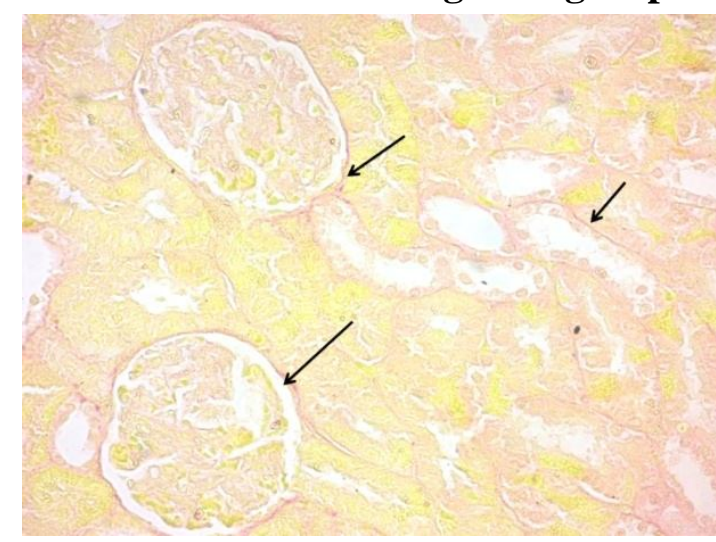

Fig (13): Showing normal distribution of collagen fibers which appeared as fine collagen fibers "stained red" around the renal corpuscles and the tubules $(\rightarrow)$.

(Control -Sirius red $\mathrm{x400)}$

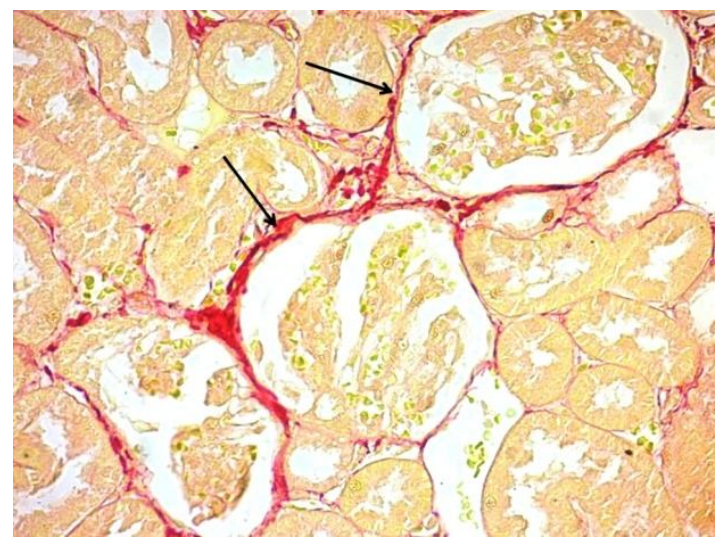

Fig (14): Showing increase deposition of collagen fibers in the interstitiam around the renal corpuscles and tubules $(\rightarrow)$.

(Sodium valproate ingested group - Sirius red $x 400$ ) 


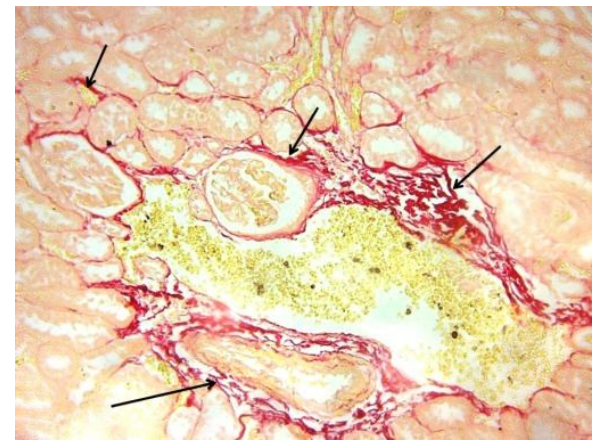

Fig (15): Showing increase deposition of collagen fibers around the renal corpuscles and tubules as well as blood vessels $(\rightarrow)$.

(Sodium valproate ingested group - Sirius red $\mathbf{x 2 0 0 )}$

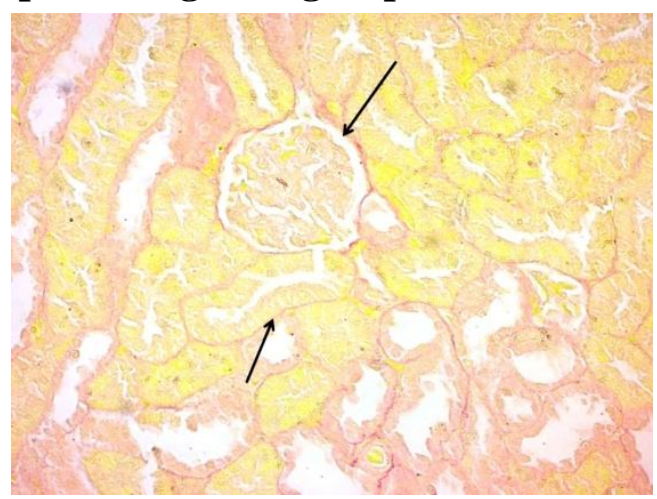

Fig (16): Showing normal distribution of collagen fibers which appeared as fine collagen fibers "stained red" around the renal corpuscles and the tubules $(\rightarrow)$.

(Cinnamon extract ingested group - Sirius red $x 400$ )

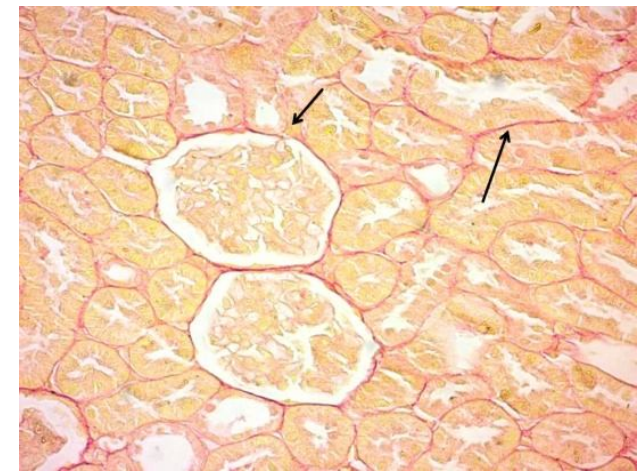

Fig (17): Showing moderate decrease amount of collagen fibers around the renal corpuscles and tubules as compared to Sodium valproate group $(\rightarrow)$.

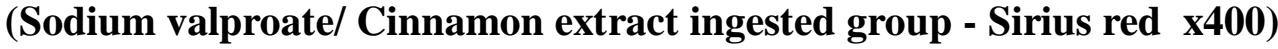




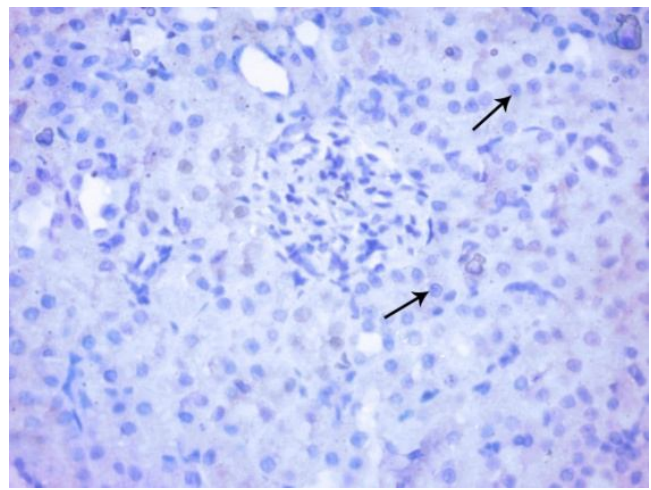

Fig (18): Showing negative (-ve) immunoreactions for Caspase-3 within the cytoplasm of the tubular cell. The nuclei are seen due to counter stain with Haematoxlyin $(\rightarrow)$.

(Control -Caspase-3 x 400)

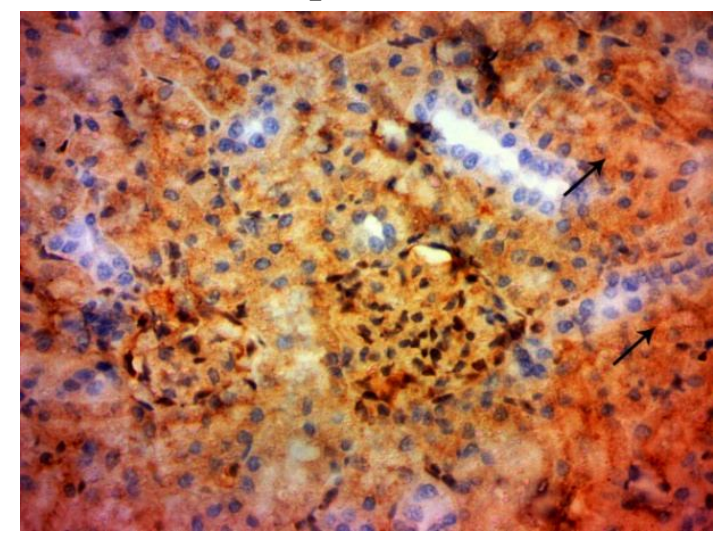

Fig (19): Showing strong positive (+ve) immunostaining reaction for Caspase-3 in the form of dark brown granules $(\rightarrow)$ within the cytoplasm.

(Sodium valproate ingested group - Caspase-3 x 400)

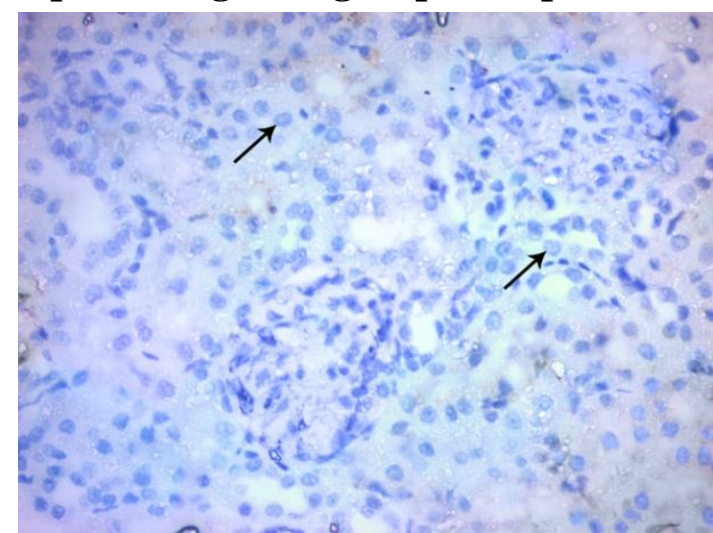

Fig (20): Showing negative (-ve) immunoreactions for Caspase-3 within the cytoplasm of the tubular cell. The nuclei are seen due to counter stain with Haematoxlyin $(\rightarrow)$.

(Cinnamon extract ingested group - Caspase-3 x 400) 


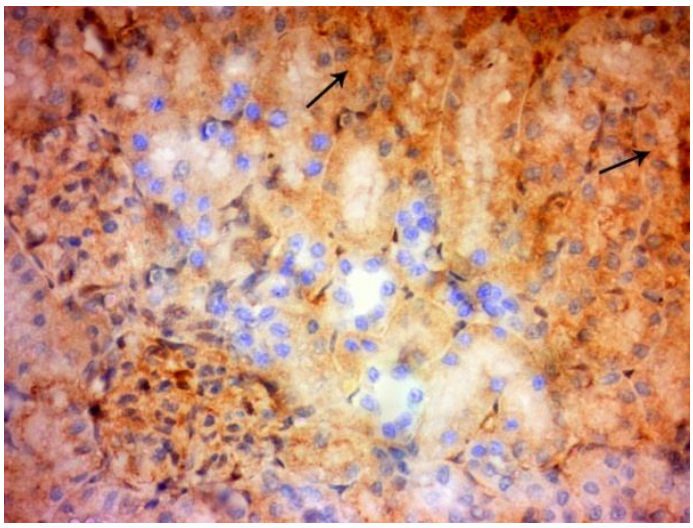

Fig (21): Showing moderate positive immunoreaction for Caspase-3 $(\rightarrow)$ in the form of dark brown granules within the cytoplasm of tubular cells.

(Sodium valproate/ Cinnamon extract ingested group - Caspase-3 x 400)

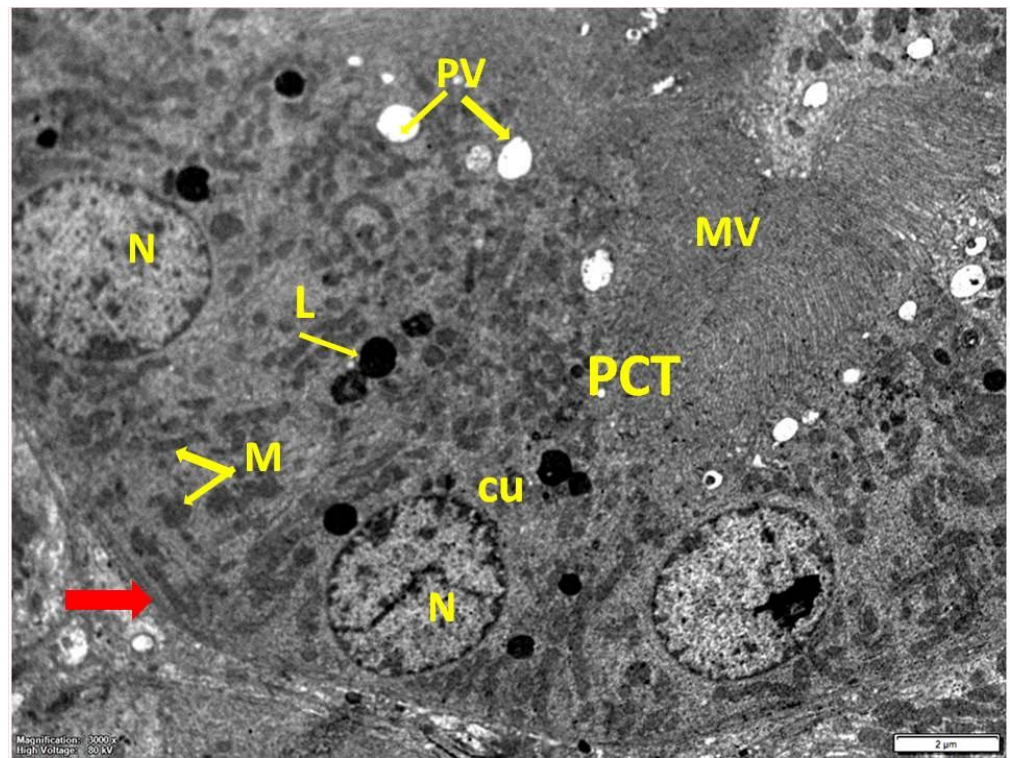

Fig (22): Showing a part a proximal convoluted tubule (PCT) lined by cubical epithelium (CU) and rest on a thin regular and well-defined basement membrane (red arrow). The cytoplasm contains rounded euchromatic nuclei $(\mathrm{N})$ abundant electron dense mitochondria (M), Lysosomes (L), and pinocytic vesicles (PV). Notice, many apical closely packed microvilli (MV).

(Control - X3000) 


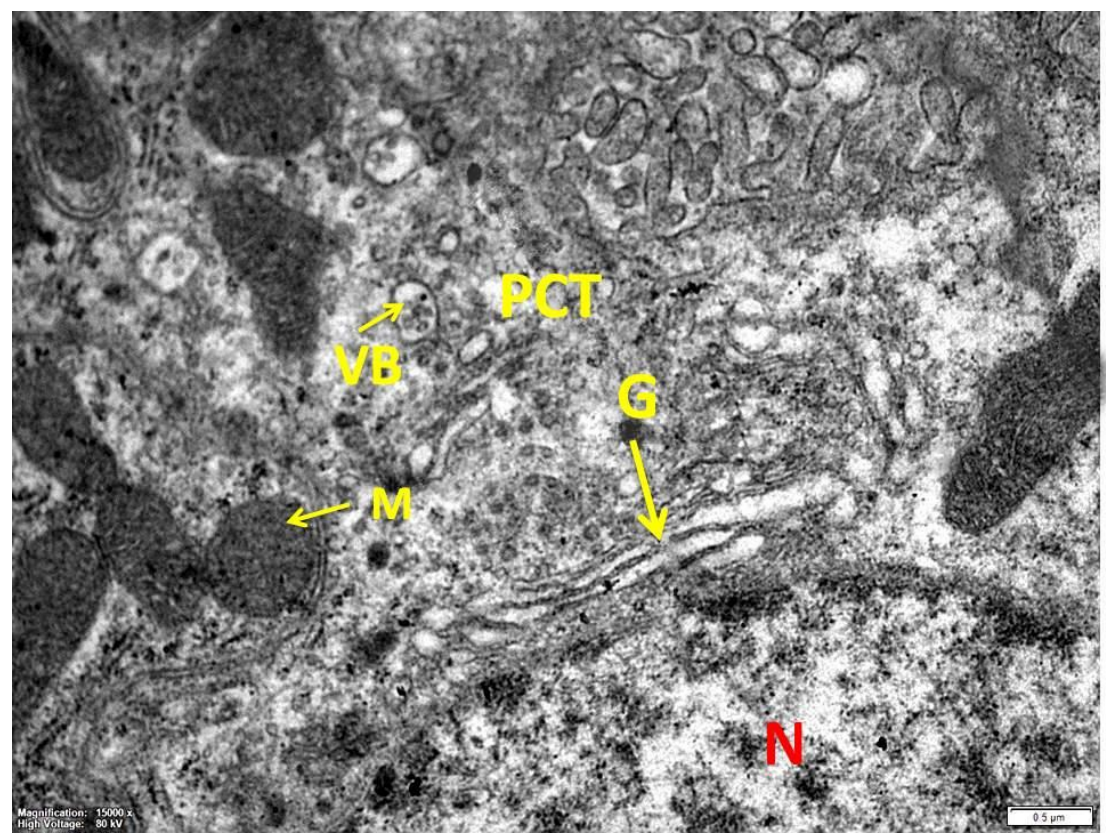

Fig (23): Part of proximal convoluted tubule (PCT) containing Golgi apparatus (G) near to the euchromatic nucleus $(\mathrm{N})$, formed of flattened closely stacked cisternae and vesicles with smooth membranes. Notice, the electron dense mitochondria (M) with intact cristae and multivesicular bodies (VB).

\section{(Control - X 15000)}

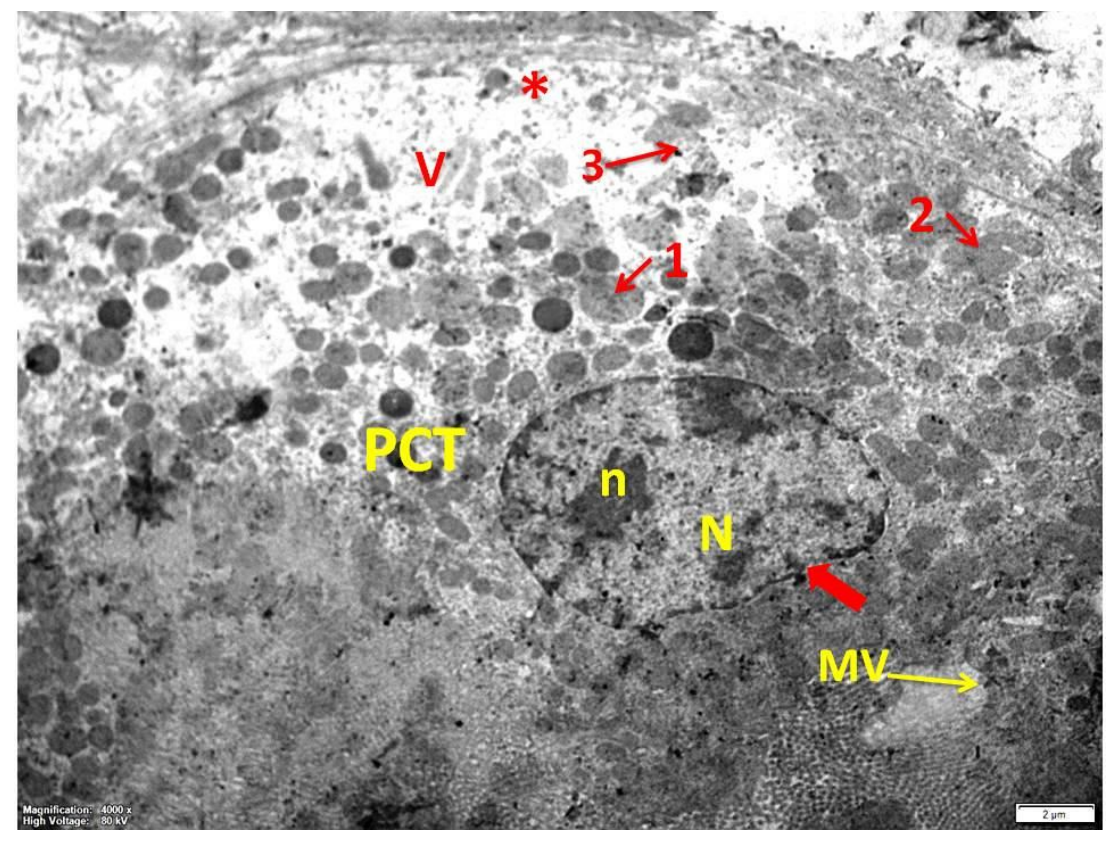

Fig (24): Showing cells of proximal convoluted tubule (PCT) with extensive vacuolated coarse poorly defined cytoplasm $(\mathrm{V})$. Notice, numerous swollen $(1 \rightarrow)$, sticky $(2 \rightarrow)$, and degenerated $(3 \rightarrow)$ mitochondria dissociated from the basal infolding $(*)$. Notice, focal loss of the apical microvilli (MV) and the nucleus (N) with prominent nucleolus (n) and irregular nuclear envelop (red arrow).

(Sodium valproate ingested group - $\quad \mathrm{X} 4000)$ 


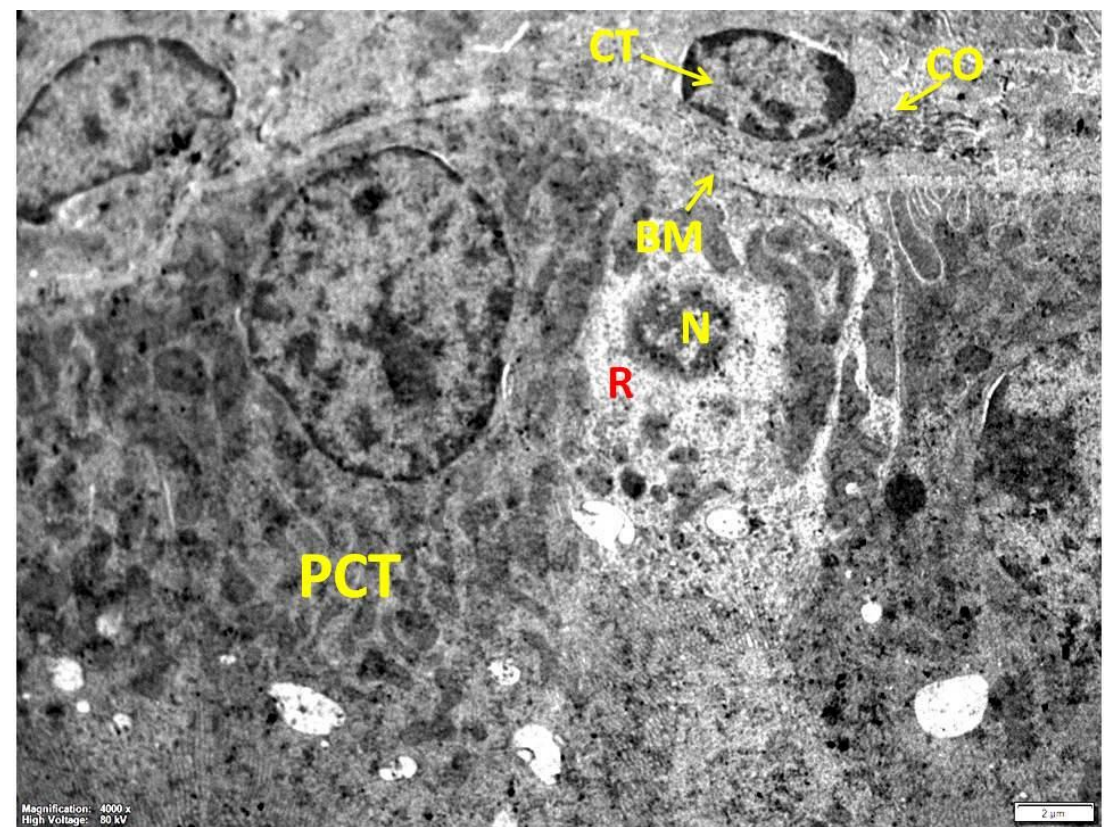

Fig (25): Showing cell of proximal convoluted tubule (PCT) containing small sized pyknotic nucleus $(\mathrm{N})$ with loss of their nuclear membrane and condensation of their chromatin, rarefied cytoplasm (R) and focal thickening of basement membrane (BM). Notice, increase deposition of collagen fibers (CO) and connective tissue cells (CT) around tubule.

(Sodium valproate ingested group - $\mathbf{X 4 0 0 0 )}$

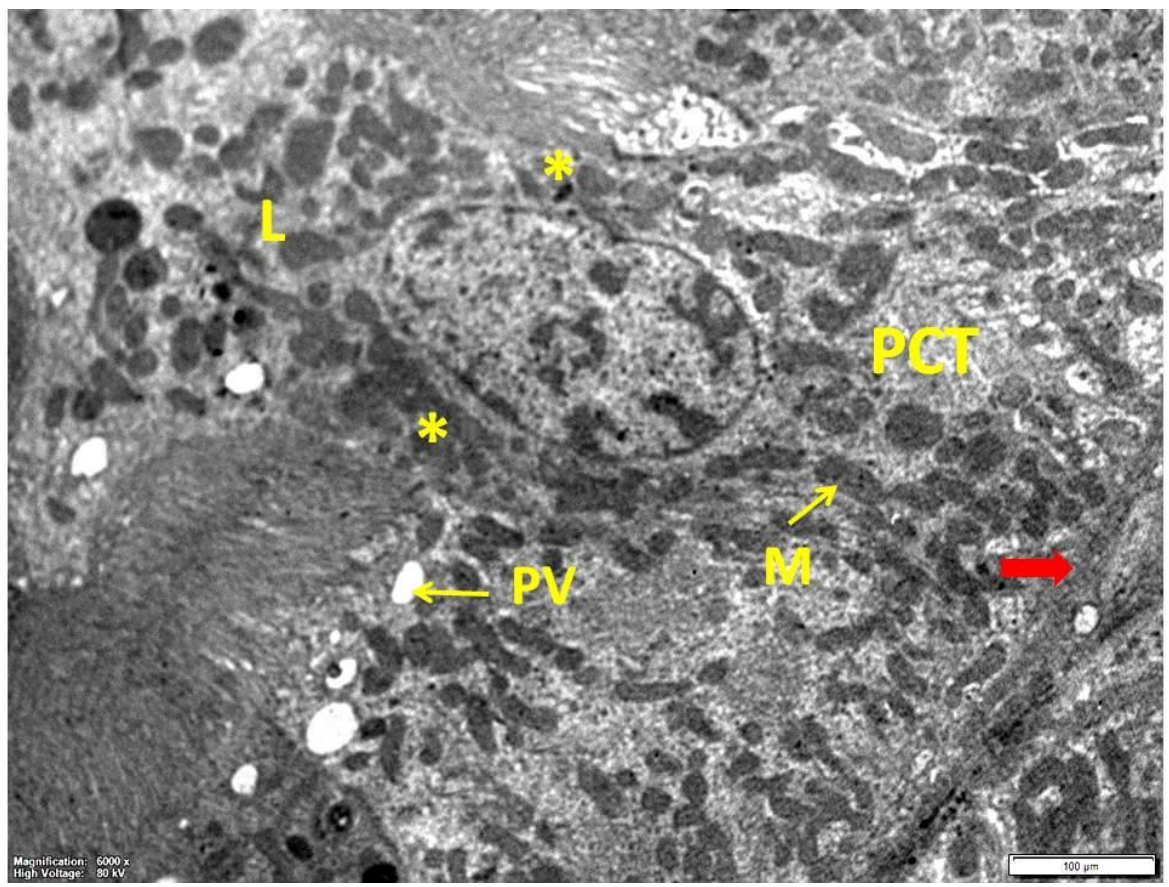

Fig (26): Showing disruption of apical cell membrane of proximal convoluted tubule (PCT) and loss of apical microvilli (*) with extrusion of their content into the lumen (L). Notice, the thin regular and well-defined basement membrane (red arrow), abundant electron dense mitochondria (M), and pinocytic vesicles beneath the microvilli (PV).

(Sodium valproate ingested group - $\mathbf{X 6 0 0 0 )}$ 


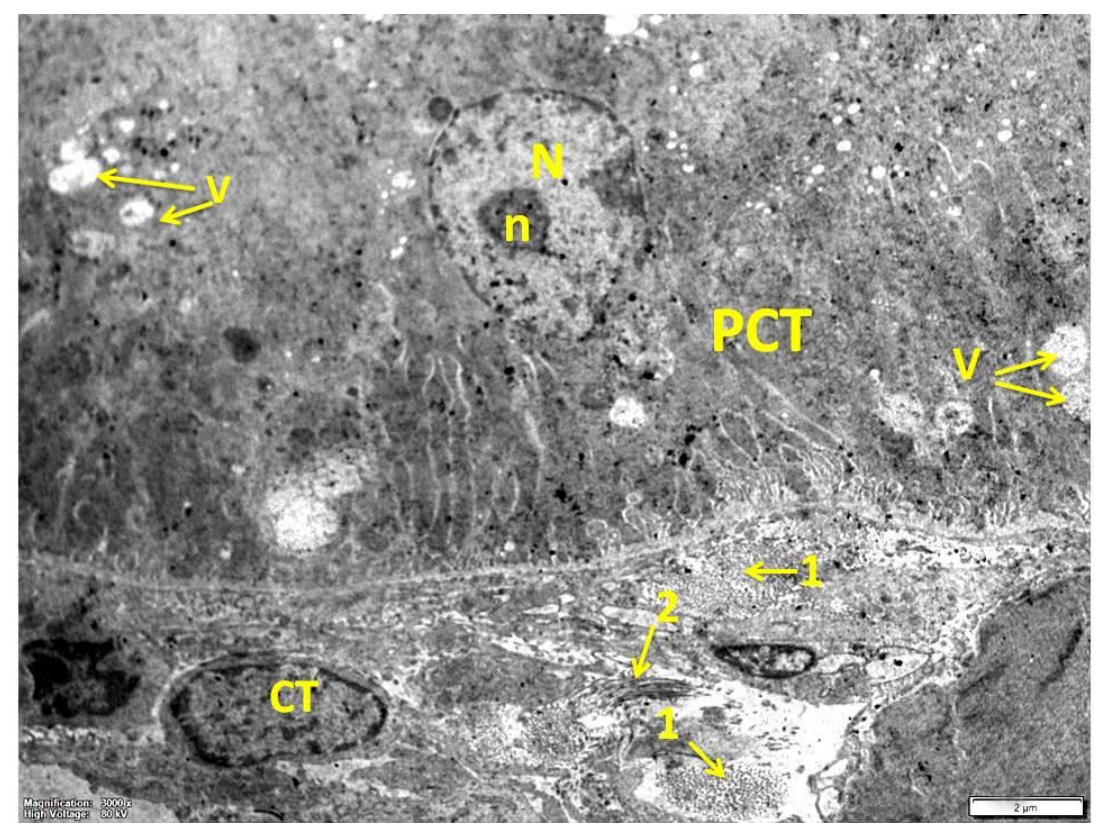

Fig (27): Showing Increase deposition of cross $(1 \rightarrow)$ and longitudinal $(2 \rightarrow)$, sections of collagen fibers and connective tissue cells (CT) around tubules. Notice, multiple cytoplasmic vacuolation $(\mathrm{V})$, euchromatic nucleus $(\mathrm{N})$ with prominent nucleolus $(\mathrm{n})$ of proximal convoluted tubule (PCT) .

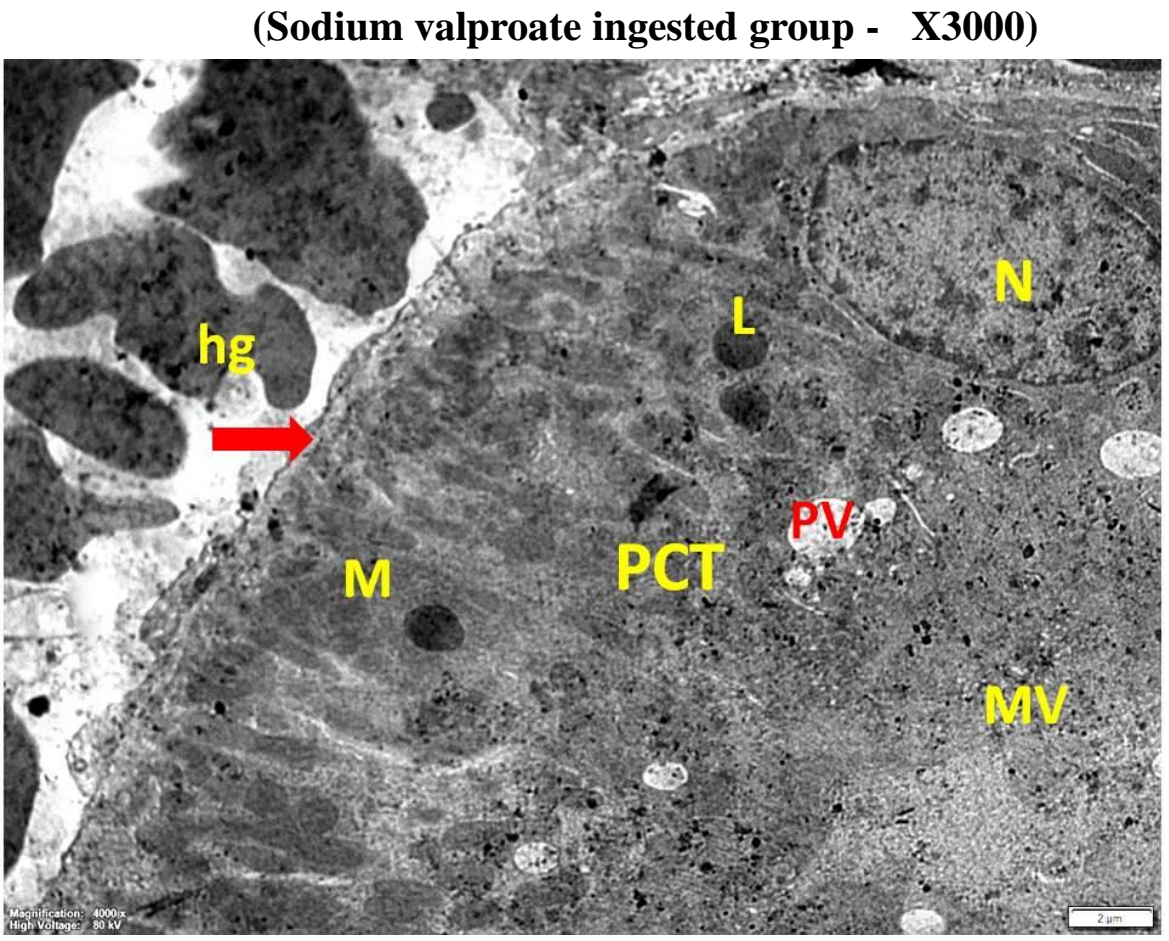

Fig (28): Showing interstitial hemorrhage in between the tubules (hg) and a part of a proximal convoluted tubule (PCT) rest on thin regular and well-defined basement membrane (red arrow), having many apical closely packed microvilli (MV), and rounded euchromatic nucleus (N). Notice, abundant electron dense mitochondria (M), Lysosomes (L) and pinocytic vesicles (PV). 


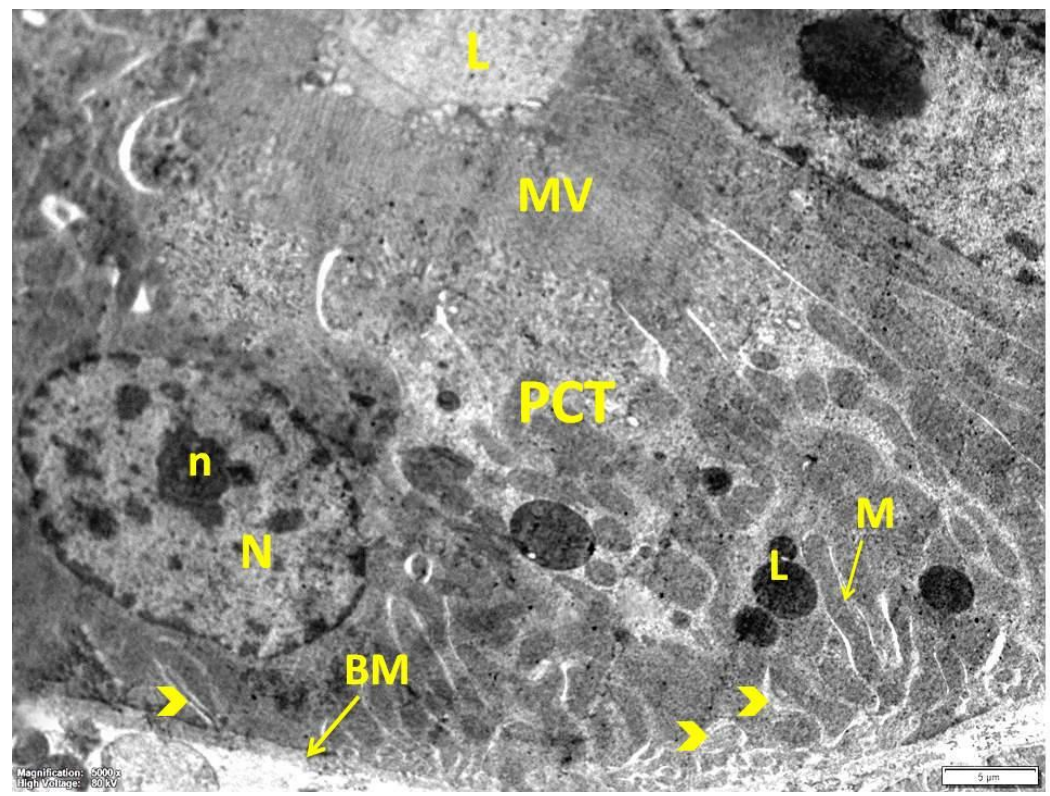

Fig (29): Showing a part a proximal convoluted tubule (PCT) with narrow lumen (L) rest on a thin regular and well-defined basement membrane ((BM). The cytoplasm contains rounded euchromatic nucleus $(\mathrm{N})$ with prominent nucleolus $(\mathrm{n})$, abundant electron dense mitochondria (M) arranged along deep basal infoldings (arrow head), and Lysosomes (L). Notice, many apical closely packed microvilli (MV).

\section{(Cinnamon extract ingested group - X5000)}

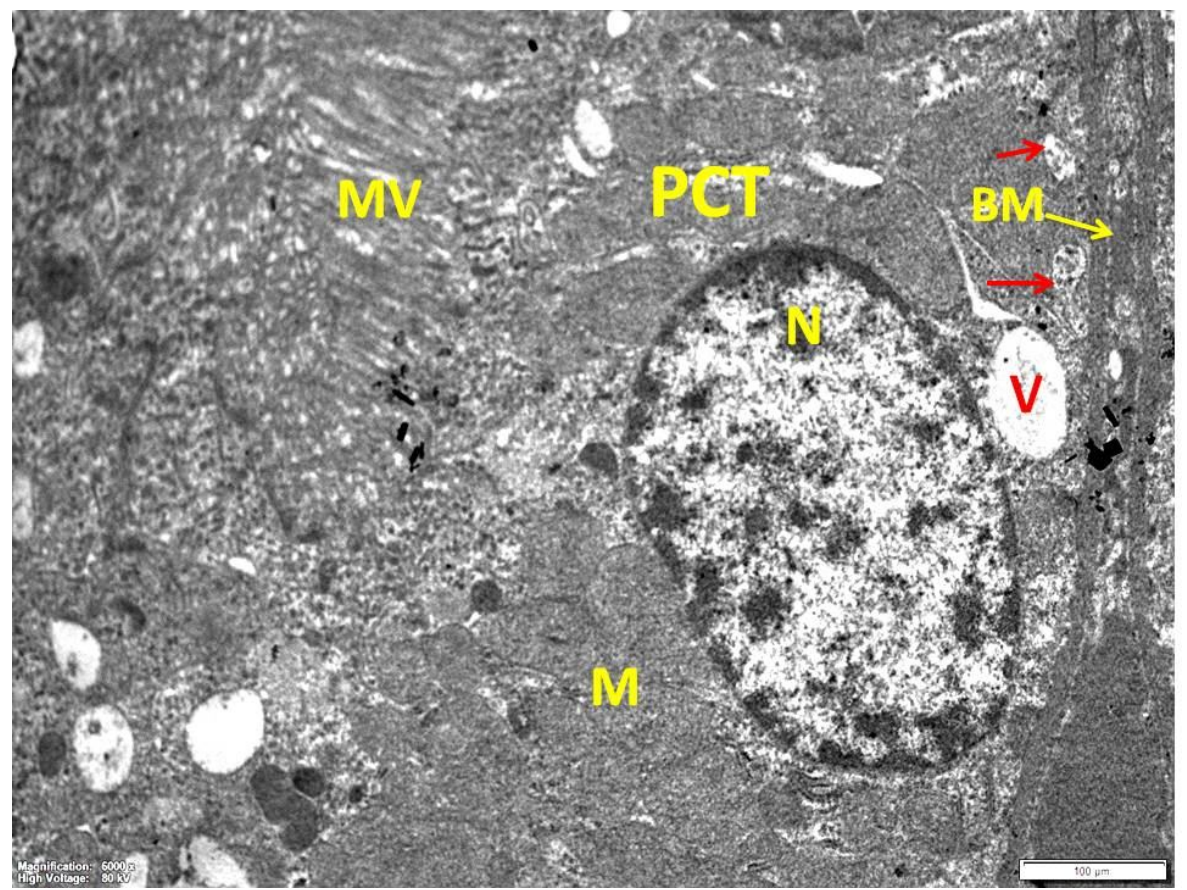

Fig (30): Showing a part of two cells of proximal convoluted tubule (PCT) rest on a thin regular and well-defined basement membrane ((BM) having many apical closely packed microvilli (MV). The cytoplasm contains rounded euchromatic nucleus $(\mathrm{N})$ and abundant electron dense mitochondria $(\mathrm{M})$, few of them are degenerated (red arrow). Notice, the vacuole in the basal part (V).

(Sodium valproate/ Cinnamon extract ingested group - X6000) 
Table (1): The mean values of BUN mg/dl level among all rats of the experimental groups at the end of the experiment (Mean \pm SD)

\begin{tabular}{|c|c|c|c|c|}
\hline \multirow{2}{*}{ Parameters } & & & \\
\cline { 2 - 5 } & BUN mg/dl & $\begin{array}{c}\text { Creatinine } \\
\text { level (sCr) } \\
\mathbf{m g} / \mathbf{d l}\end{array}$ & $\begin{array}{c}\text { Area percent of } \\
\text { collagen fibers }\end{array}$ & $\begin{array}{c}\text { Area Percent of } \\
\text { caspase-3 expression }\end{array}$ \\
\hline $\begin{array}{c}\text { GI } \\
\text { N=6 }\end{array}$ & $\begin{array}{c}29.1 \pm 5.7 \\
\mathbf{a , b}\end{array}$ & $0.42 \pm 0.07^{\mathbf{a}, \mathbf{b}}$ & $7.02 \pm 1.1^{\mathbf{a}, \mathbf{b}}$ & $1.74 \pm 0.33^{\mathbf{a}, \mathbf{b}}$ \\
\hline $\begin{array}{c}\text { GII } \\
\text { N=6 }\end{array}$ & $62.38 \pm 9.5^{\mathbf{c}}$ & $1.76 \pm 0.37^{\mathbf{c}}$ & $42.39 \pm 28.75^{\mathbf{c}}$ & $19.76 \pm 3.11^{\mathbf{c}}$ \\
\hline $\begin{array}{c}\text { GIII } \\
\text { N=6 }\end{array}$ & $\begin{array}{c}29.12 \pm \\
3.87^{\mathbf{d}}\end{array}$ & $0.48 \pm 0.18^{\mathbf{d}}$ & $7.18 \pm 1.66^{\mathbf{d}}$ & $1.44 \pm 0.217^{\mathbf{d}}$ \\
\hline $\begin{array}{c}\text { GIV } \\
\text { N=6 }\end{array}$ & $\begin{array}{c}46.1 \pm 4.39 \\
\mathbf{e}\end{array}$ & $1.38 \pm 0.20^{\mathbf{e}}$ & $17.6 \pm 1.53^{\mathbf{e}}$ & $12.64 \pm 2.2$ \\
\hline p-value of F- test & $0.000^{*}$ & $0.000^{*}$ & $0.000^{*}$ & $0.000^{*}$ \\
\hline
\end{tabular}

$\mathrm{N}$ : Number of animals

(ANOVA test

a, b, c, d, e Post Hoc “Tukey" tests

a: GI vs GII ,

b: G1vs GIV

c: GII vs GIII

d: GII vs GIV

e: GIII vs GIV

\section{DISCUSSION}

The experiment of Mazaheri et al. (2011) concerning children on antiepileptic treatment with valproic acid recorded signs of renal tubular dysfunction. Heidari et al. (2018) reported that Valproic acid (VPA) induced Fanconi syndrome and mitochondrial dysfunction.

Natural plant-derived antioxidants are in high demand than synthetic antioxidants because of their potential in health promotion, disease prevention, and their improved safety and consumer acceptability. Keshvari et al. (2013) and Beji et al. (2018) mentioned that Cinnamon possess a distinct antioxidant activity, which is especially attributed to the presence of phenolic and polyphenolic substances.

In $H \& E$ stained sections of sodium valproate ingested adult male albino rats, many renal corpuscles showed shrinkage of their glomerular tuft of capillaries with widening of their capsular space. Few corpuscles revealed distortion of their normal appearance. This is inconsistent with the report of Galaly et al. (2014) who found marked histological changes in the kidney of VPA-treated mice. Many corpuscles were shrunk with partial degeneration of glomerular tuft. This could be explained by Heidari et al. (2018) who found that VPA elevated 
kidney ROS levels, reduced tissue antioxidant activity, increased lipid peroxidation and depleted renal glutathione stores. Moreover, they found that renal mitochondrial function was hampered in VPA-treated animals. All these data indicate the contribution of oxidative stress, mitochondrial dysfunction, and its consequent events in VPA-induced renal injury.

Some convoluted tubules of sodium valproate ingested adult male albino rats showed widening of their lumen, reduced cellular height and presence of cellular debris in their lumen. These results were in agreement with Galaly et al. (2014) who stated that the increase in the size of the tubules resulted in increased proximal reabsorption, which in turn caused glomerular hyperfiltration via hyperabsorption. The hyperfiltration increased glomerular capillary pressure which caused endothelial mesangial and podocyte injuries with the increased filtration of proteins to tubular lumen, resulting in tubulointenstial inflammation (Sanchez-Lozada et al., 2004).

Many tubular cells of sodium valproate ingested adult male albino rats showed extensive vacuolation of the cytoplasm and some nuclei of these cells were deeply stained. In accordance with the present results, the finding of Jassim (2013) who observed that kidney tissue treated with valproate revealed that the proximal and the distal convoluted tubules show hydropic changes (small white vacules within the cytoplasm). Galaly et al. (2014) found that the kidney tubules of VPAtreated mice were also affected as indicated by the partial desquamation of epithelial cells lining the tubules and nuclear degeneration manifested by pyknosis.

In the current study, renal cortex of sodium valproate ingested adult male albino rats (GII) revealed interstitial mononuclear cellular infiltrations around renal corpuscles and tubules. Increased deposition of connective tissue elements around renal corpuscles and tubules noticed in some sections. This was in accordance with the finding of Galaly et al. (2014) who observed lymphocytic infiltration in renal tissue of mice treated with VPA. Gezginci-Oktayoglu et al. (2016) also found mononuclear cell infiltration and accumulation of collagen fibers in the necrotic areas, in renal tissue of rats treated with VPA. They propose that VPA-activated tubules release soluble products such as monocyte chemoattractant protine-1 (MCP-1) to stimulate mononuclear cell infiltration into the interstitium and differentiation into macrophages; these cells release proinflammatory cytokines such as TNF- $\alpha$ and IL-1 $\beta$ that stimulate ROS production and renal injury. Galaly et al. (2014) and Amrani et al. (2016) also observed lymphocytic infiltration in renal tissue of mice treated with VPA.

In the current study, cinnamon extract ingested adult male albino rats showed normal histological appearance of the renal cortex. This was in accordance with the finding of Morgan et al. (2014); (Mhammad et al., 2015) and Ghonim et al.,. (2017) who found that kidney sections treated with cinnamon extract alone showed normal histological appearance of glomeruli and renal tubules when compared to control group . 
In the present study, renal cortex sections of sodium valproate/ cinnamon extract ingested rats, showed less damaging features than that demonstrated in sodium valproate group. These results were supported by the work of Beenish et al. (2018) who showed improvement in morphological appearance of glomeruli in rats treated with cinnamon aqueous extract via gavage tube $2 \mathrm{hr}$ before daily subcutaneous injection of bisphenol A. This can be explained by presence of polyphenols in cinnamon.

In the present study, examination of periodic acid Schiff (PAS) stained sections of sodium valproate group, revealed mild to week positive PAS reaction in the basement membrane surrounding renal corpuscles and glomerular capillaries together with focal loss of basement membrane around most tubules. There was also loss of the brush border of the cells lining most of the proximal convoluted tubules. These were explained by Singh et al. (2004) who stated that free radical induced oxidative stress has been implicated in the etiology of kidney diseases. Lipid peroxidation (LPO) is probably the most largely considered product produced by free radicals and hence is regarded as an excellent biomarker of oxidative stress (Messaoudi et al., 2009).

Lipid peroxidation (LPO) mediated by oxygen free radicals, is believed to be an important cause of destruction and damage to cell membranes and has been suggested to be a contributing factor to the development of VPA mediated tissue damage (Chaudhary and Parvez, 2012).

In the present study, examination of sirius red stained sections revealed increase collagen fibers around the renal corpuscles and tubules of sodium valproate group (GII). These results were in agreement with Gezginci-Oktayoglu et al. (2016) who found increase collagen-I in the kidneys of VPA-treated rats. This finding was explained by Chaudhary et al. (2014) who have reported that VPAinduced oxidative stress. The high levels of ROS are associated with inflammation. Lei et al. (2014) added that inflammation contributes to progression of fibrosis .

The reduced collagen fibers distribution in sodium valproate/ cinnamon extract ingested group could be explained by the results of Kwon et al. (2011) who concluded that treatment with cinnamon extract inhibited maturation of major histocompitability complex (MHC) II (+) antigen presenting cells (APCs) These results suggested the potential of cinnamon extract as an anti-inflammatory agent by targeting the generation of regulatory APCs and interleukin (IL-10) (+) regulatory $\mathrm{T}$ cells. The antifibrogenic effect of cinnamon extract is associated with regulation of extracellular matrix accumulation and attenuation of the inflammatory process.

In the current study, sodium valproate group showed a significant increase in the levels of the apoptotic marker caspace-3. These results were in agreement with Chen et al. (2007) who found that VPA induces apoptosis of microglia cells and that the apoptosis of microglia was accompanied by disruption of the mitochondrial membrane potential. Miyatake et al. (2007) suggested that VPA affects membrane trafficking which leads to enhanced sensitivity to cell-wall damage in fission yeast. Cansu et al. 
(2010) stated that VPA trigger apoptotic and degenerative effects on rat uterine and ovarian cells and this may be due to the Histone deacetylase (HDAC) inhibitors activity of VPA with the induction of cell cycle arrest.

The observed decrease in the levels of the apoptotic marker caspase- 3 in in sodium valproate/ cinnamon extract ingested group coincided with the work of $Y u \ddot{c}$ e et al. (2013) who found that cinnamon bark oil consumption for a long period tended to decrease the testicular apoptotic germ cells of male healthy Wistar rats. The tendency to decrease in apoptotic germ cell count after cinnamon bark oil ingestion may possibly related to the decreased LPO level as evidenced by a significant decrease in malondialdehyde (MDA) level. It has been reported that an increase in free radicals results in increased testicular apoptotic germ cell (Maheshwari et al., 2009). However, phenolic compounds like ellagic acid have antiapoptotic effect against LPO-induced testicular apoptotic cell count (Türk et al., 2011).

In the present study, electron microscopic examination of kidney sections of sodium valproate ingested adult male albino rat revealed ultrastructual alteration as compared to that of the control group. The cells of the PCT showed extensive vacuolated coarse poorly defined cytoplasm and numerous swollen, sticky and degenerated mitochondria, in addition to partial loss of the apical microvilli. Moreover, small sized pyknotic nucleus and focal thickening of basement membrane were observed. These results were in agreement with the finding of Galaly et al.
(2014) who found marked alteration on the proximal tubules of mice given VPA $(100 \mathrm{mg} / \mathrm{kg})$ for three weeks .

The observed findings of nephrotoxicity, as illustrated by cytological alterations of mitochondria, could be explained by Pourahmad et al. (2012) who attributed this alteration to the increased production of free radicals and/or a decreased free radical scavenging capacity.

Basile et al. (2012) stated that loss of the renal brush border is due to the breakdown of cytoskeletal elements. The cytoskeletal response is attributed to the sensitivity of actin polymerization on cellular ATP levels. The reduction in cellular ATP results in a loss of (filamentous) f-actin from apical microvilli, terminal web junctional complexes and stress fibers.

Electron microscopic examination of kidney section of sodium valproate/ cinnamon extract ingested group revealed moderate improvement. Keshvari et al. (2013) and Beji et al. (2018) mentioned that Cinnamon possess a distinct antioxidant activity, which is especially attributed to the presence of phenolic and polyphenolic substances.

The significant increases in blood urea and creatinine level in sodium valproate group were in agreement with GezginciOktayoglu et al. (2016) and Heidari et al. (2018) who noticed a significant increase in the levels of urea and creatinine in the serum of VPA-treated rats, and they attributed this finding to renal damage. In addition, serum creatinine level elevated in adult patients with epilepsy using valproate (Hamed et al., 2018). 
MONA H. M. A. HAMOUDA et al.,

On the other hand, the blood urea and creatinine reduced in sodium valproate/ cinnamon extract ingested group. These results were supported by the findings of Hasanein et al. (2012) who noticed improvement in serum urea and creatinine in obese rats suffering from diabetes treated with cinnamon water extract and suggested that this improvement was due to useful effect of cinnamon due to its ability in improving renal functions and protects renal glomeruli against oxidative damage via increasing both the levels and activities of antioxidant status. Kassaee et al. (2017) also found that the blood urea and creatinine levels were normalized in the diabetic rats treated with Cinnamon extract. Besides the antioxidant action, cinnamon is well-known to have antidiabetic (Iniabohs, 2017).

\section{CONCLUSION}

In conclusion, the present study revealed that Sodium valproate aggravated the histological structure of the renal cortex but fortunately these changes were reversible and could be mildly corrected by administration of antioxidants as Cinnamon extract.

\section{REFERENCES}

1. Abdelwahab, S. I.; Mariod, A. A. and Tahaetal, M. M. E. (2014): Chemical composition and antioxidant properties of the essential oil of Cinnamomum altissimum Kosterm. (Lauraceae). Arabian Journal of Chemistry, 90(1):249-254.

2. AL-Khamas, A.J.H. (2018): Effect of Cinnamon Zeylanicum Bark Water Extract on Male Diabetic Albino Rats Fertility. Bas.J.Vet.Res, 17(1):123-135.

3. Amrani,A.; Benaissa, O.; Boubekri, N.; Biod, K.; Djabari, R.; Beroa,N. and Zama1, D. (2016): Impact of Chrysanthemum fontanesii extract on sodium valproate mediated oxidative damage in mice kidney. Journal of Applied Pharmaceutical Science, 6 (4):67-071.

4. Bancroft, J.D. and Gamble, M. (2015): In: Theory and practice of histological Techniques, 6th edition. pbl. Churchill Livingstone, Edinburgh, London, Melbourne; 201-217.

5. Basile, D. P.; Anderson, M. D. ; and Sutton, T. A. (2012): Pathophysiology of Acute Kidney Injury. Compr Physiol, 2(2): 1303-1353.

6. Beenish, H.; Rana, R.; Muhammad, S. A. and Khan, A.A. (2018): Comparative Effects of Cinnamon Extract and Green Tea Against Bisphenol- A Induced Damage in Rat Kidney. JIIMC., 13(1):12-16.

7. Beji, R.S.; Khemir, S.; Wannes, W. A.; Ayari, K. and Ksouri, R. (2018): Antidiabetic, antihyperlipidemic and antioxidant influences of the spice cinnamon (Cinnamomum zeylanicumon) in experimental rats. Braz. J. Pharm. Sci., 54(2): 175761175768 .

8. Cansu, A.; Erdogan, D.; Serdaroglu, A.; Coskun, Z. and Gurgen, S. G.(2010): Histologic and morphologic effects of valproic acid and oxcarbazepine on rat uterine and ovarian cells. Epilepsia, 51(1):98-107.

9. Charles, D.J. (2013): Cinnamon. Antioxidant Properties of Spices, Herbs and Other Sources, Chapter 16; pbl. Springer Science, Business Media, New York; 231- 243.

10. Chaudhary, S.; Ganjoo, P.; Raiusddin, S. and Parvez, S. (2014): Nephroprotective activities of quercetin with potential relevance to oxidative stress induced by valproic acid. Protoplasma, 252(1): 209-217.

11. Chaudhary, S. and Parvez, S. (2012): An in vitro approach to assess the neurotoxicity of valproic acid-induced oxidative stress in cerebellum and cerebral cortex of young rats. Neuroscience, 225:258-268.

12. Chen, P.S.; Wang, C.C.; Bortner, C.D.; Peng, G.S.; Wu, X.; Pang, H.; Lu, R.B.; Gean, P.W.; Chuang, D.M. and Hong, J.S. (2007): Valproic acid and other histone deacetylase inhibitors induce microglial apoptosis and attenuate lipopolysaccharideinduced dopaminergic neurotoxicity. Neuroscience, 149:203-212. 
13. Dhillon, N. and H?gler, W. (2011): Fractures and Fanconi syndrome due to prolonged sodium valproate use. Neuropediatrics, 42:119121.

14. Du, W.X.; Olsen, C.W.; Avena-Bustillos, R.J.; McHugh, T.H.; Levin, C.E. and Friedman, M. (2009): Effects of allspice, cinnamon, and clove bud essential oils in edible apple ? Ims on physical properties and antimicrobial activities. J Food Sci., 74:372378.

15. Galaly, S. R.; Abdella, E. M.; Mohammed, H. M. and khadrawy, S. M. (2014 ): Effects of royal jelly on genotoxicity and nephrotoxicity induced by valproic acid in albino mice. Beni - Suef University Journal of basic and applied sciences, $31-15$.

16. Gezginci-Oktayoglu, S.; Turkyilmaz, I. ; Ercin, M.; Yanardag, R. and Bolkent, S. (2016) : Vitamin $U$ has a protective effect on valproic acid-induced renal damage due to its anti-oxidant, anti-inflammatory, and antifibrotic properties. Protoplasma, 253:127-135.

17. Ghonim, A.; Abdeen, A.; El-Shawarby, R.; Abdel-Aleem, N.; El-Shewy, E.; Abdo, M. and Abdelhiee, E. (2017): Protective effect of cinnamon against cadmium-induced hepatorenal oxidative damage in rats. International Journal of Pharmacology and Toxicology, 5 (1): 17-22.

18. Hamed, S. A.; Rageh, T.A.; Mohamad, A.O. and Abou Elnour, S.M. (2018): Renal dysfunctions / injury in adult epilepsy patients treated with carbamazipine or valproate. Expert Rev Clin Pharmacol., 11(8):819-824

19. Hasanein, M. A.; Abdel Gawad, S. H. and Abd El-Megeid, A. A. (2012): Effect of Water Extract Prepared from Green Tea, Black Tea and Cinnamon on Obese Rats Suffering from Diabetes. World Applied Sciences Journal, 20 (7): 976-987.

20. Heidari, R.; Jafari,F.; Khodaei, F.; Yeganeh, B. S. and Niknahad, H. (2018): Mechanism of valproic acid-induced Fanconi syndrome involves mitochondrial dysfunction and oxidative stress in rat kidney. Nephrology, 351-361.

21. Iniabohs, O.M. (2017): All rights reserved protective effects of aqueous extract of cinnamon on diabetes-induced nephrotoxicity in Wistar rats. J Appl Sci Environ Manag., 21:504-508.

22. Jassim, A.M. (2013): Protective Effect of Petroselinum crispum(parsley)extract on histopathological changes in liver ,kidney and pancreas induced by Sodium Valproate in male Rats. Kufa Journal For Veterinary Medical Sciences, 4 (1) : 20-27.

23. Jaya, S.; Deval, R. and Mallikajuna, K. A (2014): review on hepatoprotective activity of some medicinal plants. IJIPR, 5(2): 395-404.

24. Kassaee, S. M.; Goodarzi, M.T. and Oshaghi, E.A. (2017): Renoprotective Effects of Trigonella foenum and Cinnamon on Type 2 Diabetic Rats. Avicenna J Med Biochem, 5 (1): 17-21.

25. Keshvari, M.; Asgary, S.; Jafariandehkordi, A.; Najafi, S. and GhoreyshiYazdi, S.M. (2013): Preventive effect of cinnamon essential oil on lipid oxidation of vegetable oil. ARYA Atheroscler, 9(5):280286.

26. Kwon, H.K.; Hwang, J.S.; Lee, C.G.; So, J.S.; Sahoo, A.; Im, C.R.; Jeon, W.K.; Ko, B.S.; Lee, S.H. and Park, Z.Y. (2011): Cinnamon extract suppresses experimental colitis through modulation of antigenpresenting cells. World J Gastroenterol., 17:976-986.

27. Lee, B.J.; Kim, Y.J.; Cho, D.H.; Sohn, N.W. and Kang, H. (2011): Immunomodulatory effect of water extract of cinnamon on antiCD3-induced cytokine responses and p38, JNK, ERK1/2, and STAT4 activation. Immunopharmacol Immunotoxicol., 33(4):714722 .

28. Lei, Y.; Wang, K.; Deng, L.; Chen, Y.; Nice, E.C. and Huang, C. (2014): Redox regulation of inflammation: old elements, a New Story. Med Res Rev., 35(2): 306-340.

29. Loscher, W. (2002): Basic pharmacology of valproate: A review after 35 years of clinical use for the treatment of epilepsy. CNS Drugs., 16 (10): 669-694

30. Maheshwari, A.; Misro, M. M.; Aggarwal, A.; Sharma, R.K. and Nandan, D. (2009): Pathways involved in testicular germ cell apoptosis induced by $\mathrm{H} 2 \mathrm{O} 2$ in vitro. FEBS J., 276:870-881. 
31. Mandal, S.; DebMandal, M.; Saha, K. and Pal, N.K. (2011): In vitro antibacterial activity of three Indian spices against methicillinresistant Staphylococcus aureus. Oman Med J., 26(5): 319-323.

32. Maneenin, C.; Burawat, J.; Maneenin, N.; Nualkaew, S.; Arun, S.; Sampannang, A. and Iamsaard, S. (2018): Antioxidant Capacity of Momordica charantia Extract and its Protective Effect on Testicular Damage in Valproic AcidInduced Rats Int. J. Morphol., 36(2): 447-453.

33. Mazaheri, M.; Samaie, A. and Semnani,V. (2011): Renal tubular dysfunction measured by $\mathrm{N}$-acetyl beta glucosaminidase/ creatinine activity index in children receiving antiepileptic drugs: a randomized controlled trial. Ital J Pediatr., 37(21):14.

34. Messaoudi, I.; El Heni, J.; Hammouda, F.; Saïd, K. and Kerkeni, A. (2009): Protective effects of selenium, zinc, or their combination on cadmium-induced oxidative stress in rat kidney. Biol Trace Elem Res., 130:152-161.

35. Mhammad, H.A.;, Jubrail, A.M. S. and Najeeb, M. K. (2015): Impact of Cinnamon Extract on Liver, Kidneys and Spleen of Diabetic Rats International Journal of Chemical and Biomolecular Science., 1(4): 248-254.

36. Miyatake, M.; Kuno, T.; Kita, A.; Katsura, K.; Takegawa, K.; Uno, S.;Nabata, T. and Sugiura, R. (2007): Valproic acid affects membrane trafficking and cell-wall integrity in fission yeast. Genetics, 175: 1695-1705.

37. Morgan, A.M.; El-Ballal, S.S.; El-Bialy, B.E. and EL-Borai, N. B. (2014): Studies on the potential protective effect of cinnamon against bisphenol A- and octylphenol-induced oxidative stress in male albino rats. Toxicology Reports, 1: 92-101.

38. Pourahmad, J.; Eskandari, M.R.; Kaghazi, A. and Shaki, F. (2012): A new approach on valproic acid-induced hepatotoxicity: involvement of lysosomal membrane leakiness and cellular proteolysis. Toxicol in Vitro, 26:545-551.

39. Robinson , D.G.; Ehlers, U.; Herken, U.E.; Herrmann, B.; Mayer, F. and Schurmann, F.W. (1987): Method for preparation for electron microscopy. An introduction for the biochemical sciences. Muhlethaler K.pbl. Springer-verlag. Berlin, Heidelberg, New YorkLondon - Paris-Tokyo. ISBN: 3-540-17592-X.

40. Sanchez-Lozada, L.G.; Iapia, E., Johnson, R.J.; Rodriguez-Iturbe, B. and HerreraAcosta, J. (2004): Glomerular haemodynamic changes associated with arteriolar lesions and tubulointerstitial inflammation. Kidney Int., 65:1971-1972.

41. Singh, D.; Chander, V. and Chopra, K. (2004): Quercetin, a bioflavonoid, attenuates ferric nitrilotriacetate-induced oxidative renal injury in rats. Drug Chem Toxicol., 27:145156.

42. Su, L.; Yin, J.J.; Charles, D.; Zhou, K.; Moore, J. and Yu, L. (2007): Total phenolic contents, chelating capacities and radicalscavenging properties of black peppercorn, nutmeg, rosehip, cinnamon and oregano leaf. Food Chem., 100: 990-997.

43. Toktam, F.; aghihi, A. J.; Javad, M.; Vandad, S.; Shahin, A. and Padideh, G. (2012): Role of Omega-3 fatty acids in preventing metabolic disturbances in patients on olanzapine plus either sodium valproate or lithium: a randomized double-blind placebocontrolled trial . DARU Journal of Pharmaceutical Sciences, 20 (1):43-50.

44. Türk, G.; C, eribas, A.O.; S ahna, E. and Ates s, ahin, A. (2011): Lycopene and ellagic acid prevent testicular apoptosis induced by cisplatin. Phytomedicine, 18:356-361.

45. Wang, L.; Liu, F.; Jiang, Y.; Chai, Z.; Li, P.; Cheng, Y.; Jing, H. and Leng, X. (2011): Synergistic antimicrobial activities of natural essential oils with chitosan ? lms. J Agric Food Chem., 59(23):12411-12419.

46. Williams, D.B. and Carter, C.B. (1996): Transmission Electron Microscopy. A Textbook for Materials Science. 2nd edition, pbl. Springer - verlag. Berlin. Heidelberg, New York, London, 721-756.

47. Yu“ ce, A.; Tu“ rk, G.; C, $\operatorname{eribas}_{\text {s, S.; So }}$ nmez, M.; C, ifte, M. and Güvenc, $M$. (2013): Effects of cinnamon (Cinnamomum zeylanicum) bark oil on testicular antioxidant values, apoptotic germ cell and sperm quality. Andrologia, 45: 248-255. 


\section{تأثير فاللبروات الصوديوم على تركيب القشرة الكلوية لذكور الجزذان البيضاء البالفة ودور القرفة}

منى حسين محمد احمد حمودة ـ فاطمة سيد عبد العال ـ فطومه حسن يوسف المشد قسم الهستولوجى - كلية الطب ( بنات ) - جامعة الأزهر

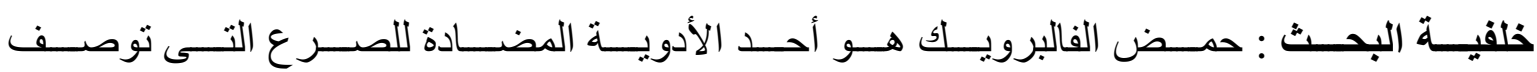

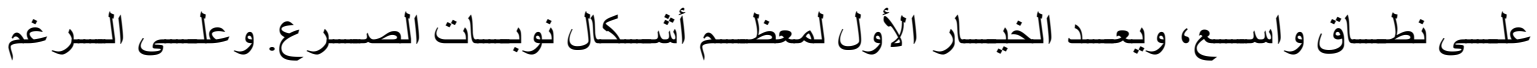

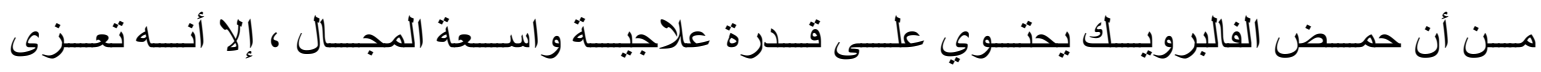

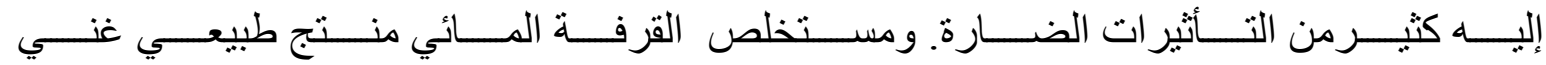

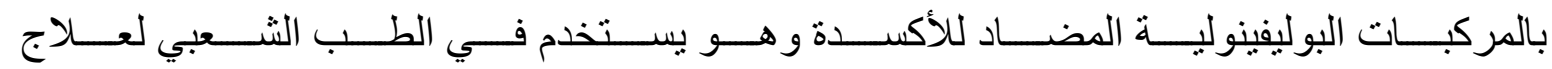

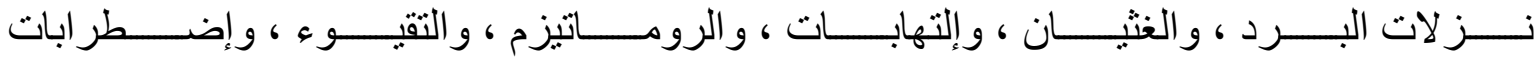
الدورة الثهرية.

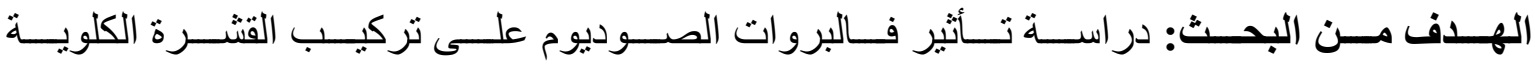
لذكور الجرذان البيضاء البالغة وتقييم الدور الوقائي المحتمل للقرفة.

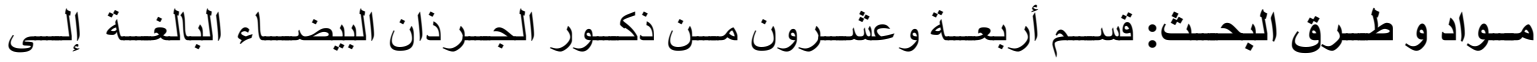

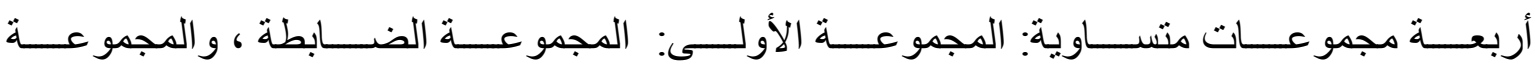

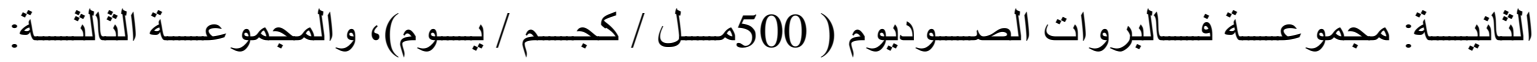

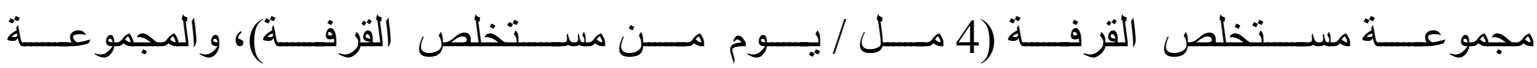
الر ابعة :مجموعة فالبروات الصوديوم مع مستخلص القرفة.

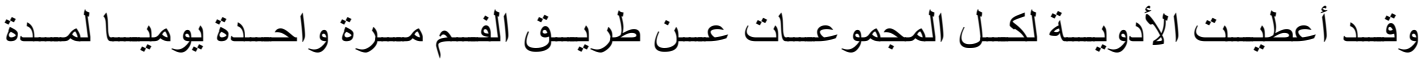
أربعة أسابيع باستخدام أنبوب معدى.

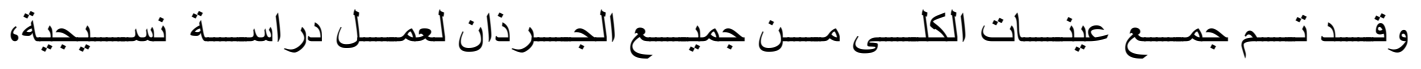

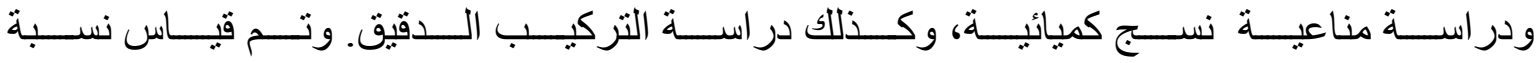

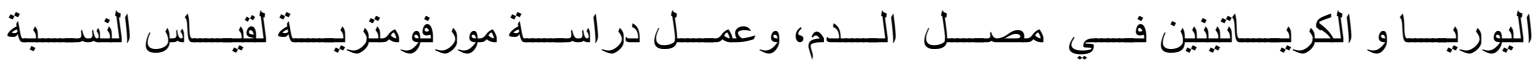




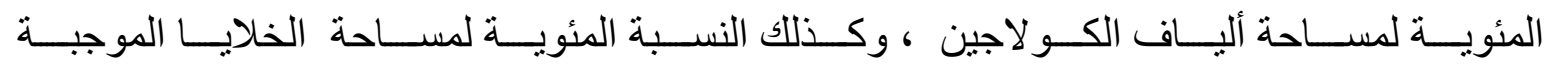
. Caspase-3 J

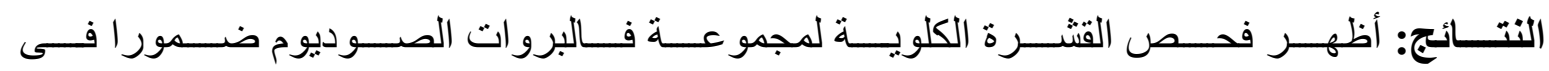

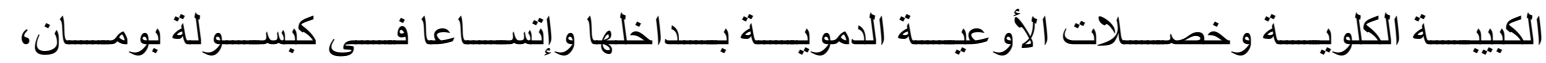

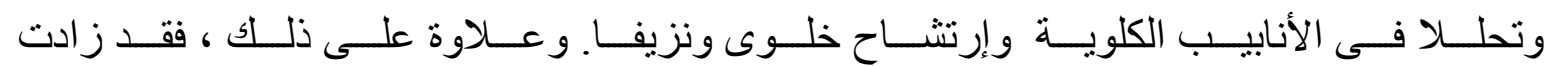

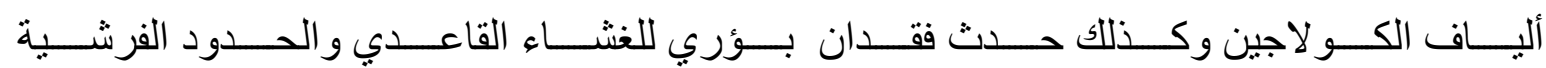

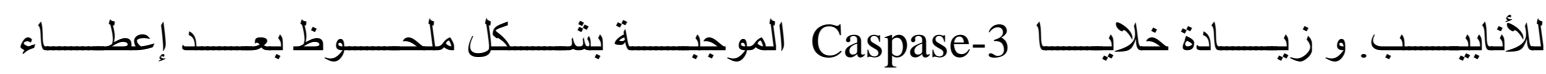

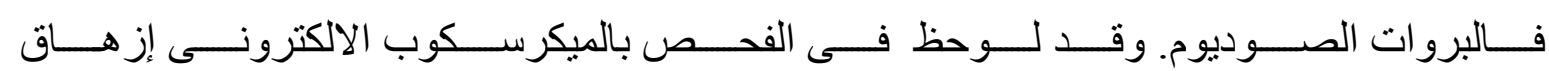
العصارة الخلوية وتحلل الميتوكوندريا وفقدان الزغرية القمية و ضمور النواة.

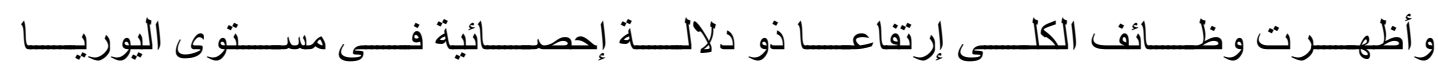

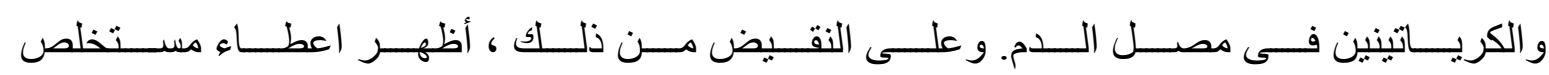

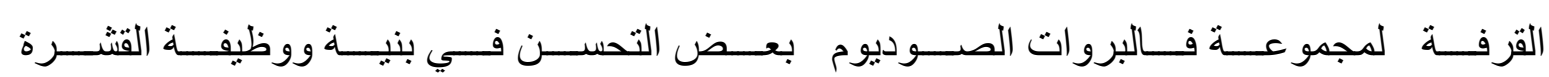
الكلوية.

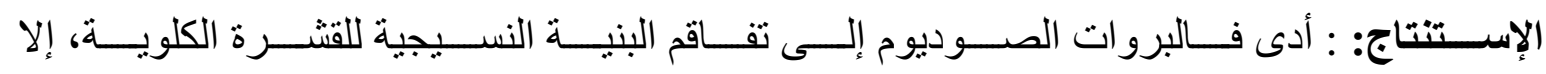

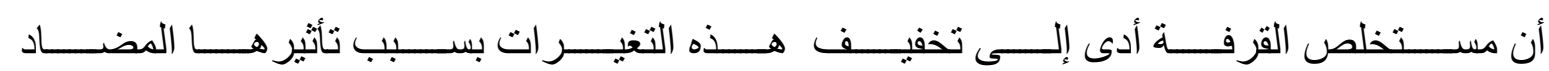

